University of Rhode Island

DigitalCommons@URI

Open Access Master's Theses

2009

\title{
An Examination of the Relationships Among Cardiorespiratory Fitness Status, Body Mass Index, Appetite and Grelin
}

Jennifer Arts

University of Rhode Island

Follow this and additional works at: https://digitalcommons.uri.edu/theses

\section{Recommended Citation}

Arts, Jennifer, "An Examination of the Relationships Among Cardiorespiratory Fitness Status, Body Mass Index, Appetite and Grelin" (2009). Open Access Master's Theses. Paper 1430.

https://digitalcommons.uri.edu/theses/1430

This Thesis is brought to you for free and open access by DigitalCommons@URI. It has been accepted for inclusion in Open Access Master's Theses by an authorized administrator of DigitalCommons@URI. For more information, please contact digitalcommons-group@uri.edu. 


\begin{abstract}
AN EXAMINATION OF THE RELATIONSHIPS AMONG CARDIORESPIRATORY FITNESS STATUS, BODY MASS INDEX, APPETITE AND GHRELIN
\end{abstract}

BY

JENNIFER ARTS

A THESIS SUBMITTED IN PARTIAL FULFILLMENT OF THE REQUIREMENTS FOR THE DEGREE OF MASTER OF SCIENCE

IN NUTRITION AND FOOD SCIENCES 
MASTER OF SCIENCE THESIS

OF

JENNIFER ARTS

APPROVED:

Thesis Committee:

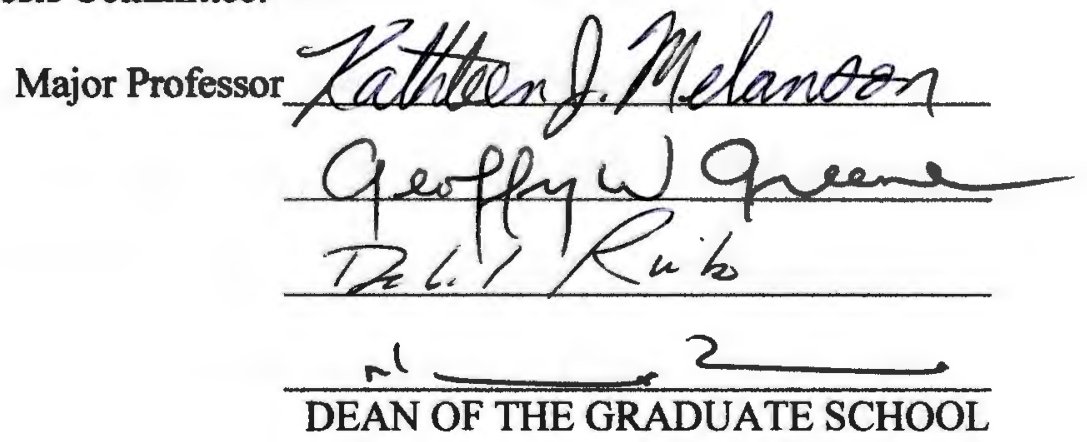

UNIVERSITY OF RHODE ISLAND

2009 


\section{ABSTRACT}

Problem Statement: Obesity and its related metabolic disorders rank among the leading causes of illness and mortality worldwide. The prevalence of obesity has led researchers to focus on body weight regulation and the balance between energy intake and energy expenditure.

Background: Studies have suggested that ghrelin is involved in both short and long term energy balance. Previous research has examined the relationships among BMI, ghrelin and appetite but few studies have investigated the role that fitness status plays in relation to these.

Methods: Data from two studies that were previously conducted in the Energy Metabolism Laboratory were combined for a secondary data analysis. One hundred nine subjects ( 87 females, 22 males; $19.4 \pm 2.1$ years; BMI $22.9 \pm 3.9 \mathrm{~kg} / \mathrm{m}^{2}$ ) were included in the analysis. Cardiorespiratory fitness $\left(\mathrm{VO}_{2} \mathrm{max}\right)$ was estimated by the Queen's Coilege Step test and self-reported physical activity was determined by the International Physical Activity Questionnaire. Ratings of appetite (by $100 \mathrm{~mm}$ visual analog scales), plasma total ghrelin (by RIA) and insulin (by ELISA) were analyzed following a $10 \mathrm{~h}$ fast and $30 \mathrm{~min}$ after a standardized meal.

Results: Ghrelin was significantly correlated with BMI in both the fasting ( $\mathrm{r}=-0.290$, $\mathrm{p}=0.005)$ and fed $(\mathrm{r}=-0.381, \mathrm{p}=0.001)$ states. Significant negative correlations were also found between $\mathrm{VO}_{2} \max$ and both fasting ghrelin $(\mathrm{r}=-0.305, \mathrm{p}=0.003)$ and fed ghrelin ( $r=-0.336, p=0.005)$. Fasting ghrelin was also significantly correlated with vigorous physical activity $(\mathrm{r}=-0.242, \mathrm{p}=0.019)$, waist circumference $(\mathrm{r}=-0.298$, $\mathrm{p}=0.004)$ and insulin $(\mathrm{r}=-0.324, \mathrm{p}=0.012)$. Ghrelin and appetite were not significantly 
related at single time point measures $(t=0,30 \mathrm{~min})$. BMI was positively correlated with dietary restraint $(r=0.258, \mathrm{p}=0.007)$ and disinhibition $(\mathrm{r}=0.276, \mathrm{p}=0.004)$, whereas $\mathrm{VO}_{2}$ max was negatively correlated with dietary restraint $(\mathrm{r}=-0.350, \mathrm{p}<0.001)$. ANOVA indicated that subjects with BMIs above the median had significantly lower fasting ghrelin $(692.2 \pm 237.9 \mathrm{pg} / \mathrm{mL}$ vs. $802.2 \pm 266.0 \mathrm{pg} / \mathrm{mL}, \mathrm{p}=0.037)$ and fed ghrelin $(575.0 \pm 164.4 \mathrm{pg} / \mathrm{mL}$ vs. $710.2 \pm 226.4 \mathrm{pg} / \mathrm{mL}, \mathrm{p}=0.005)$ and significantly greater disinhibition (6.5 \pm 3.1 vs. $4.8 \pm 3.1, \mathrm{p}=0.005$ ) compared to those with BMIs below the median. Subjects with a higher fitness status reported significantly lower fasting satiety $(31.4 \pm 22.3$ vs. $36.8 \pm 22.2, \mathrm{p}=0.022)$, greater desire to eat $(53.3 \pm 17.5$ vs. $45.5 \pm 20.5, \mathrm{p}=0.037)$, and less dietary restraint $(7.8 \pm 5.2$ vs. $11.3 \pm 5.4, \mathrm{p}=0.001)$ compared to subjects with a lower fitness status.

Significance and Conclusions: These findings confirm previous relationships reported between BMI and ghrelin, subjective appetite and eating behaviors and corroborate lack of associations between single-point time measures of ghrelin and appetite. Additionally, results indicate that cardiorespiratory fitness may be related to circulating ghrelin levels, subjective appetite, and degree of dietary restraint. Further study is needed to determine the nature of these relationships. 


\section{ACKNOWLEDGEMENTS}

I would like to thank Dr. Kathleen Melanson, my major advisor, for her long term support. Dr. Melanson's resume enticed me to pursue the URI program and my interactions with her far surpassed any expectations I had regarding the breadth of her knowledge. Dr. Melanson provided me with immeasurable assistance and always made me feel I was a priority despite her numerous other daily demands. Her expertise, patience and attention to detail allowed me to never lose sight of my objectives. It was a privilege to have her as an advisor.

Dr. Daniel Kresge played a pivotal role in my thesis development from its early stages through to the fine-tuning process. I am grateful to him for his technical support. Dan is an in-house expert who always provided sound and reliable instruction. I was fortunate to have benefited from his knowledge.

I would also like to express my gratitude to my committee members Dr. Greene and Dr. Riebe. Along with Dr. Melanson, they truly formed a "team of experts" and provided me with constructive input throughout the thesis process.

Last but certainly not least, Dr. Cathy English, who never failed to see the "bigger picture" regarding my schedule, my thesis and my graduation. Cathy was relentlessly accommodating and flexible with my TA responsibilities. She helped to ensure that my priorities were always on course and made me feel that my individual goals were 
equally as important as department assignments. Cathy made my entire graduate experience a positive one. 


\section{PREFACE}

This thesis is a secondary data analysis examining the relationships among cardiorespiratory fitness status, BMI, ghrelin and appetite. The thesis is presented in manuscript format. The manuscript was formatted for submission to the journal Physiology and Behavior. 


\section{TABLE OF CONTENTS}

\section{$\underline{\text { Page }}$}

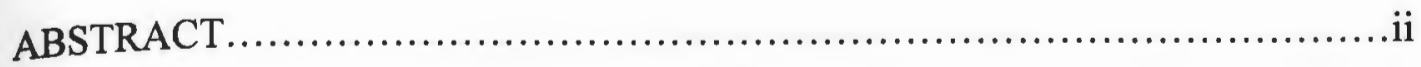

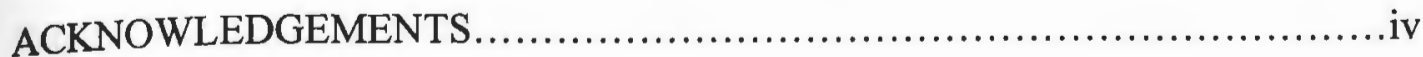

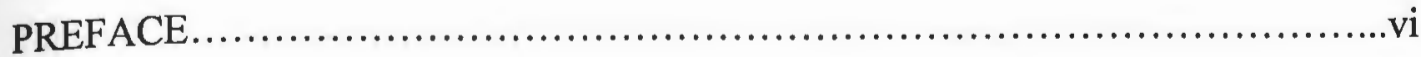

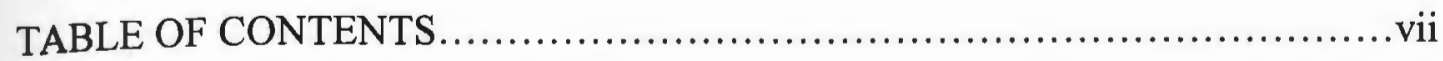

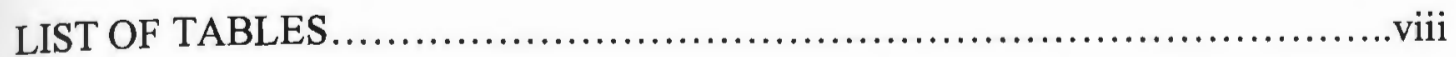

LIST OF FIGURES.............................................................

MANUSCRIPT

Abstract.................................................................

Introduction.........................................................

Methods............................................................

Results..............................................................11

Discussion...........................................................15

References........................................................21

APPENDIX A: Literature Review...............................................34

APPENDIX B: International Physical Activity Questionnaire.....................58

APPENDIX C: Three Factor Eating Questionnaire...........................661

APPENDIX D: Sample Visual Analog Scale-Appetite..........................66

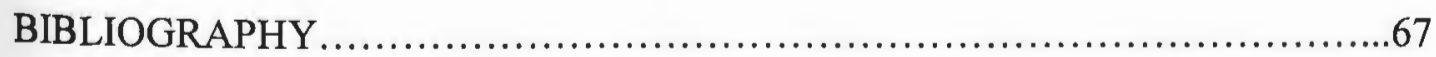




\section{LIST OF TABLES}

Table 1: Subject characteristics.

Table 2: Mean ghrelin levels by BMI category ..............................27

Table 3: Appetite scores by fitness category ...............................28

Table 4: Fasting ghrelin prediction equations................................29 


\section{LIST OF FIGURES}

Figure 1: Relationship between fasting ghrelin and BMI.......................30

Figure 2: Relationship between fed ghrelin and BMI......................... 31

Figure 3: Relationship between fasting ghrelin and estimated 32 cardiorespiratory fitness

Figure 4: Relationship between fed ghrelin and estimated cardiorespiratory .........33 fitness 


\section{MANUSCRIPT}

\section{ABSTRACT}

Studies have suggested that ghrelin is involved in both short and long term energy balance. Previous research has examined the relationships among BMI, ghrelin and appetite but few studies have investigated the role that fitness status plays in relation to these variables. Data from two studies that were previously conducted in our laboratory were combined for a secondary data analysis. One hundred nine subjects ( 87 females, 22 males; $19.4 \pm 2.1$ years; BMI $22.9 \pm 3.9 \mathrm{~kg} / \mathrm{m}^{2}$ ) were included in the analysis. Cardiorespiratory fitness was estimated by the 3 minute Queen's College Step test and the 51-item Three Factor Eating Questionnaire was used to assess cognitive restraint, disinhibition and perceived hunger. Ratings of appetite (by $100 \mathrm{~mm}$ visual analogue scale), plasma total ghrelin (by RIA) and insulin (by ELISA) were analyzed following a $10 \mathrm{~h}$ fast and $30 \mathrm{~min}$ after a standardized meal. Ghrelin was significantly correlated with $\mathrm{BMI}$ in both the fasting $(\mathrm{r}=-0.290, \mathrm{p}=0.005)$ and fed $(r=-0.381, p=0.001)$ states. Significant negative correlations were also found between estimated cardiorespiratory fitness $\left(\mathrm{VO}_{2} \mathrm{max}\right)$ and both fasting ghrelin $(\mathrm{r}=-0.305$, $\mathrm{p}=0.003)$ and fed ghrelin $(\mathrm{r}=-0.336, \mathrm{p}=0.005)$. Fasting ghrelin was also significantly correlated with vigorous physical activity $(r=-0.242, p=0.019$; by IPAQ), waist circumference $(r=-0.298, p=0.004)$ and insulin $(r=-0.324, p=0.012)$. Ghrelin and appetite ratings were not significantly related at single time point measures $(\mathrm{t}=0,30$ $\min )$. BMI was positively correlated with dietary restraint $(r=0.258, p=0.007)$ and disinhibition $(r=0.276, p=0.004)$, whereas $\mathrm{VO}_{2} \max$ was negatively correlated with dietary restraint $(r=-0.350, p<0.001)$. ANOVA indicated that subjects with BMIs 
above the median had significantly lower fasting ghrelin $(692.2 \pm 237.9 \mathrm{pg} / \mathrm{mL}$ vs. 802.2 $\pm 266.0 \mathrm{pg} / \mathrm{mL}, \mathrm{p}=0.037)$ and fed ghrelin $(575.0 \pm 164.4 \mathrm{pg} / \mathrm{mL}$ vs. $710.2 \pm 226.4$ $\mathrm{pg} / \mathrm{mL}, \mathrm{p}=0.005)$ and significantly greater disinhibition $(6.5 \pm 3.1$ vs. $4.8 \pm 3.1, \mathrm{p}=0.005)$ compared to those with BMIs below the median. Subjects with a higher cardiorespiratory fitness status reported significantly lower fasting satiety $(31.4 \pm 22.3$ vs. $36.8 \pm 22.2, \mathrm{p}=0.022)$, greater desire to eat $(53.3 \pm 17.5$ vs. $45.5 \pm 20.5, \mathrm{p}=0.037)$, and less dietary restraint $(7.8 \pm 5.2$ vs. $11.3 \pm 5.4, \mathrm{p}=0.001)$ compared to subjects with a lower fitness status. These findings confirm previous relationships reported between BMI and ghrelin, subjective appetite and eating behaviors and corroborate lack of associations between single-point time measures of ghrelin and appetite. Additionally, results indicate that cardiorespiratory fitness may be related to circulating ghrelin levels, subjective appetite, and degree of dietary restraint. Further study is needed to determine the nature of these relationships. 


\section{INTRODUCTION}

Obesity and its related metabolic disorders rank among the leading causes of illness and mortality worldwide [1]. The prevalence of obesity has led researchers to focus on body weight regulation and the balance between energy intake and energy expenditure. Ghrelin is a recently discovered hormone that appears to be associated with both short and long term body weight regulation [2]. Ghrelin plays an important role as a short term regulator of appetite through its involvement in meal initiation. Plasma ghrelin levels rise before meals and decrease after meals [3]. Studies on rodents indicate that ghrelin infusion not only promotes weight gain by increasing food intake but also by decreasing energy expenditure and fat catabolism [4-6]. Intravenous infusion of ghrelin in humans increased food intake in both lean and obese subjects [7]. In addition, higher ghrelin levels have been linked to lower resting metabolic rate and thermic effect of food $[8,9]$. Collectively, these findings support a role for ghrelin in both energy intake and in energy expenditure.

Ghrelin levels fluctuate with body weight. Research has demonstrated that circulating concentrations are low in obese individuals and increase with weight loss $[10,11]$. Due to the role that exercise plays in weight loss, recent studies have explored the effects that exercise has on ghrelin [11-15]. Exercise is an established method to increase energy expenditure. Because exercise training improves fitness status, promotes weight loss and improves overall health, there has been recent research devoted to examining the effects of exercise on ghrelin levels. A chronic exercise-induced energy deficit may be associated with higher ghrelin levels. This was demonstrated in long term exercise interventions $[11,16]$. These increases, however, 
often occur along with weight loss so it is difficult to determine if the increases in ghrelin are due to the weight loss or to physical activity itself. More research is necessary to determine the mechanism responsible for this increase.

Understanding body weight regulating hormones is also essential in determining the role that fitness plays in regulating appetite. Hunger suppression is observed immediately after exercise [17-19] but compensatory effects on food intake occur in the long run to compensate for an average of $30 \%$ of energy expended in physical activity [19]. Other research has also explored the relationship between dietary restraint and exercise. It was hypothesized that high dietary restraint would be associated with a tendency for disinhibition and increased post-exercise energy intake [20]. This was not observed in overweight males [20] or in female dieters [21]. This may be attributed to the fact that increases in energy expenditure from physical activity may not be immediately compensated for by increases in energy intake [22]. If fitness status modifies these relationships has yet to be determined.

Few studies have directly examined fitness status and its relation to ghrelin. The question of whether fit individuals have higher levels of ghrelin has yet to be fully investigated. The primary purpose of this study is to examine relationships among fitness, BMI, and ghrelin and to determine their independent effects on appetite. A better understanding of these relationships will provide insight into the mechanisms that govern body weight regulation and the role that exercise training plays in this process. Determining if ghrelin levels are a function of fitness status may also clarify the relationships between fitness and appetite. This study will also assist researchers in planning human subject studies based on subject characteristics. 


\section{METHODS}

\section{Participants}

Subjects were normal weight, healthy male and female volunteers recruited from the university community using flyers, class announcements and newspaper advertisements. All participants provided voluntary, written informed consent. The University of Rhode Island Institutional Review Board approved the experimental protocol and procedures.

Study design

Data sets from two studies that were previously conducted in our laboratory were combined for a secondary data analysis including one hundred nine subjects ( $\mathrm{n}=87$ females, $\mathrm{n}=22$ males). The Ghrelin and Appetite Response to Feeding (GARF) study consisted of seventy-two females and twenty-two males. Exclusion criteria included: an inability to donate blood due to anxiety or a bleeding disorder, an allergy to any component of the test meal, pregnancy or lactation, and age younger than 18 years. Participants reported to the laboratory after a 12-hour overnight fast. Visual analogue scales, which were used to assess hunger, satiety and desire to eat were completed before and 30 minutes after the consumption of a breakfast shake (Boost, Novartis Medical Nutrition, Minneapolis, MN). The breakfast shake contained $68.3 \%$ carbohydrate, $16.7 \%$ protein and $15 \%$ fat and provided $25 \%$ of each participant's estimated resting energy expenditure as calculated by the WHO equation (males $=(15.3$ $x w t)+679),($ females $=(14.7 x w t)+746)($ WHO, 1985$)$. The average kilocalorie content of the shake was $448.1 \mathrm{kcal}$ for males and $347.9 \mathrm{kcal}$ for females. Fasting and 
30 minute postprandial blood samples were obtained from an antecubital vein for analysis of ghrelin, glucose, and insulin.

The GRAIN Study consisted of seventeen females ages 18-26 years. Exclusion criteria included: any disorder or medication known to influence metabolism or appetite, clinically-diagnosed insulin resistance, diabetes mellitus, serious illnesses, history of or current clinically-diagnosed eating disorder, weight-loss of more than five pounds in the last three months, dependence on caffeine or alcohol, allergies to any of the test foods, pregnancy or lactation.

Participants reported to the laboratory after a 10-hour overnight fast. Visual analogue scales were administered and blood draws were performed in both the fasting state and at $15,30,45,60,90,120,150$ and 180 minutes postprandially. Only the 30 minute time point was used for the purpose of this secondary data analysis. After the fasting measures, participants were served a test meal consisting of $15 \mathrm{~g}$ of a generic corn chex cereal, $15 \mathrm{~g}$ of puffed rice cereal, and $54 \mathrm{~g}$ (2 slices) of white (wheat) toast. Strawberry jam was weighed and spread on the toast and milk (1\% fat for the whole grain condition and $2 \%$ for the refined grain condition) was measured and poured over the cereal. The test meal consisted of $71 \%$ carbohydrate, $15 \%$ fat, $14 \%$ protein and provided $427.2 \mathrm{kcal}$.

Fitness and physical activity

In both protocols, cardiorespiratory fitness was estimated using the Queen's College Step Test [23]. Subjects were asked to step up and down on a 16.25 inch box to the beat of a metronome for three minutes. Post exercise heart rate was measured by palpation of the radial artery for 15 seconds immediately after and this number was 
multiplied by 4 to obtain heart rate in beats/minute and then put into the genderspecific equations for estimated $\mathrm{VO}_{2} \max$ [23]. A new equation that was developed at the University of Rhode Island was used to more accurately estimate $\mathrm{VO}_{2}$ max in male participants (Deborah Riebe, personal communication). To account for gender differences in $\mathrm{VO}_{2}$ max, the sample was grouped into fitness categories according to ACSM gender-specific cutoffs.

Self-reported physical activity was assessed using the short self-administered format of the International Physical Activity Questionnaire (IPAQ) [24]. Participants were asked to report their walking, moderate, and vigorous physical activity over the past seven days.

Blood analytes: ghrelin, glucose, insulin

Blood draws for the GARF study were performed by venipuncture, following a 12-hour overnight fast and 30 minutes after breakfast. Blood samples were drawn into two $2 \mathrm{~mL}$ EDTA tubes (Vacuette, Greiner Bio-One, Monroe, NC). The tube for analysis of ghrelin was treated with $50 \mu \mathrm{L}$ Aprotinin $/ \mathrm{mL}$ (Phoenix Pharmaceuticals, Belmont, CA, Catalog \# RK-APRO; Lot \# 422979; Dose 30.0 Trypsin Inhibitor Unit $/ 5 \mathrm{~mL}$ ). The other tube for analysis of glucose and insulin was left untreated. Both tubes were then spun at $3200 \mathrm{rpm}$ for 10 minutes on a bench top centrifuge (Unico Power Spin, Dayton, NJ). The plasma supernatant was aliquoted and kept at $-20^{\circ} \mathrm{C}$ until frozen and then was transferred to a $-80^{\circ} \mathrm{C}$ freezer for storage until batch analysis. Plasma glucose was analyzed using a Cobas Mira Plus blood analyzer (Roche Diagnostics, Branchburg, NJ). Total ghrelin was analyzed using a radioimmunoassay kit (GHRT-89HK; Linco Research, St. Charles, MO). Plasma 
insulin was measured by enzyme-linked immunosorbent assay (ELISA) (Mercodia, Uppsala, Sweden).

Blood draws for the GRAIN study were performed using a flexible in-dwelling catheter placed in the antecubital vein in the non-dominant arm through a three-way stop-cock kept patent with sterile saline. Blood draws occurred after a 10-hour overnight fast and following the test meal at $15,30,45,60,90,120,150,180$ minutes postprandial. Blood glucose levels were measured immediately using whole venous blood samples (Hemocue Auto-Analyzer, Mission Viejo, CA). Blood samples for analysis of ghrelin and insulin were centrifuged immediately at $3800 \mathrm{rpm}$ for 8 minutes. After centrifuging, $600 \mu \mathrm{L}$ of plasma supernatant was transferred to a $1.5 \mathrm{~mL}$ microcentrifuge tube pre-treated with $6 \mu \mathrm{L}$ of 4-(2-aminoethyl) benzenesulfonyl fluoride hydrochloride. Thirty $\mu \mathrm{L}$ of 1-Normal hydrochloric acid was then added. A separate untreated aliquot was used for insulin analysis. Tubes were frozen at $-80^{\circ} \mathrm{C}$. Total ghrelin was analyzed using a radioimmunoassay kit (GHRT-89HK; Linco Research, St. Charles, MO). Plasma insulin was measured by ELISA (Mercodia, Uppsala, Sweden).

Body mass index

Body mass index was calculated from height and weight measurements. Height was measured to the nearest millimeter without shoes using a wall-mounted stadiometer (Seca Acu-Height, Hamburg, Germany). Weight was measured to the nearest quarter of a pound using a calibrated physician's scale (Detecto, Webb City, $\mathrm{MO}$ ) in the GARF study and was measured to the nearest kilogram on a calibrated 
digital scale that was part of the BODPOD system in the GRAIN study (BodPod, model 2000A, Life Measurement Incorporated, Concord, CA).

Waist circumference

Waist circumference was measured in centimeters at the level of the umbilicus after normal expiration using a physician's tape measure.

Appetite

Volunteers were asked to rate their subjective appetite (hunger, satiety, desire to eat) ranging from "not at all" to "extremely" on a $10 \mathrm{~cm}$ validated visual analogue scale (VAS) [25]. Appetite assessments were administered in both fasting and fed states.

The 51-item Three Factor Eating Questionnaire (TFEQ) was also administered to measure cognitive dietary restraint, tendency for disinhibition, and perceived general hunger levels [26].

\section{Body composition}

Body composition was assessed in the Grain Study after a four hour fast using air displacement plethysmography in a self-contained system using a computerintegrated dual-chambered air plethysmograph equipped with a digital scale (BodPod, model 2000A, Life Measurements Incorporated, Concord, CA). This instrument was calibrated before each test according to manufacturer specifications. Subjects were asked to void their bladders and remove any jewelry before testing. Subjects wore a lycra swim cap and swimsuit during testing. Corrections were made for thoracic lung volume. Repeat measures were taken and percent body fat and lean body mass were 
calculated from body volume using the Siri equation [27]. This technique of measuring body composition has been validated in a wide-range of populations [28].

\section{Statistical analyses}

All analyses were performed using SPSS version 16.0 for Windows. Pearson correlations were used to describe relationships among continuous variables. BMI and $\mathrm{VO}_{2} \max$ were also analyzed categorically. A median split was used for BMI. $\mathrm{VO}_{2} \max$ groups were created according to the American College of Sports Medicine's (ACSM) gender-specific cutoffs ("lower fitness status" males: $\mathrm{VO}_{2} \max 26.6-45.50 \mathrm{ml} / \mathrm{kg} / \mathrm{min}$ females: $\mathrm{VO}_{2} \max 22.6-38.80 \mathrm{ml} / \mathrm{kg} / \mathrm{min}$, "higher fitness status" males: $\mathrm{VO}_{2} \max$ 45.51-61.2 $\mathrm{ml} / \mathrm{kg} / \mathrm{min}$, females: $\left.\mathrm{VO}_{2} \mathrm{max} 38.81-55.0 \mathrm{ml} / \mathrm{kg} / \mathrm{min}\right)$. ANOVA was performed to examine between group differences in fasting and fed ghrelin, in TFEQ restraint, hunger, and disinhibition, and in fasting satiety, desire to eat and hunger. Waist circumference, blood glucose, and insulin were entered as covariates in ANCOVA to examine their influence on the relationship between BMI and fasting and fed ghrelin. Partial correlations controlling for cardiorespiratory fitness, BMI, waist circumference, blood glucose and insulin were performed to determine their impact on the relationships between ghrelin and appetite in the fasting and fed states. Stepwise multiple regression analysis was then used to determine how well waist circumference, BMI, and insulin predicted fasting and fed ghrelin. 


\section{RESULTS}

\section{Subject Characteristics}

One hundred nine subjects were included in the analysis ( 87 females, 22 males). The mean age was $19.4 \pm 2.1$ years. The mean BMI was $22.9 \pm 3.9 \mathrm{~kg} / \mathrm{m}^{2}$ and the median BMI was $22.0 \mathrm{~kg} / \mathrm{m}^{2}$. Estimated mean $\mathrm{VO}_{2} \max$ was $40.3 \pm 8.5 \mathrm{ml} / \mathrm{kg} / \mathrm{min}$. The mean $\mathrm{VO}_{2} \max$ of the lower fit group was $36.8 \pm 2.3 \mathrm{ml} / \mathrm{kg} / \mathrm{min}$ and the mean $\mathrm{VO}_{2} \mathrm{max}$ of the higher fit group was $44.8 \pm 5.2 \mathrm{ml} / \mathrm{kg} / \mathrm{min}$. Mean values for fasting and fed ghrelin were $745 \pm 256 \mathrm{pg} / \mathrm{mL}$ and $634 \pm 204 \mathrm{pg} / \mathrm{mL}$, respectively. Subject characteristics are presented in Table 1.

Relationships among BMI, cardiorespiratory fitness, physical activity, and ghrelin As shown in Figures 1 and 2, ghrelin was significantly correlated with BMI in both the fasting $(r=-0.290, p=0.005)$ and fed $(r=-0.381, p=0.001)$ states. Significant negative correlations were also found between estimated cardiorespiratory fitness $\left(\mathrm{VO}_{2} \max \right)$ and both fasting ghrelin $(\mathrm{r}=-0.305, \mathrm{p}=0.003)$ and fed ghrelin $(\mathrm{r}=-0.336$, $\mathrm{p}=0.005$ ) as seen in Figure 3. Fasting ghrelin was also significantly correlated with reported vigorous physical activity $(r=-0.242, \mathrm{p}=0.019)$. Estimated cardiorespiratory fitness was also correlated with moderate $(r=0.249, \mathrm{p}=0.009)$, vigorous $(\mathrm{r}=0.443$, $\mathrm{p}<0.001)$, and total $(\mathrm{r}=0.369, \mathrm{p}<0.001)$ reported physical activity. ANOVA indicated that subjects with BMIs above the median had significantly lower fasting ghrelin $(692.2 \pm 237.9 \mathrm{pg} / \mathrm{mL}$ vs. $802.2 \pm 266.0 \mathrm{pg} / \mathrm{mL}, \mathrm{p}=0.037)$ and fed ghrelin $(575.0 \pm 164.4$ $\mathrm{pg} / \mathrm{mL}$ vs. $710.2 \pm 226.4 \mathrm{pg} / \mathrm{mL}, \mathrm{p}=0.005$ ) compared to those with BMIs below the median. Refer to Table 2. There were no significant differences in either fasting 
ghrelin $(p=0.099)$ or fed ghrelin $(p=0.107)$ between higher and lower fitness categories.

Relationships among BMI, cardiorespiratory fitness, physical activity, and appetite BMI was positively correlated with dietary restraint $(r=0.258, p=0.007)$ and disinhibition $(\mathrm{r}=0.276, \mathrm{p}=0.004)$, whereas $\mathrm{VO}_{2} \mathrm{max}$ was negatively correlated with dietary restraint $(\mathrm{r}=-0.350, \mathrm{p}<0.001)$. $\mathrm{VO}_{2} \max$ was positively correlated with fasting desire to eat $(r=0.327, p=0.001)$. Physical activity was not significantly associated with subjective hunger, satiety, desire to eat or with dietary restraint, disinhibition or hunger.

Fasting desire to eat was associated with fasting hunger $(r=0.801, p<0.001)$, with fasting satiety $(r=-0.394, p<0.001)$, and with dietary restraint $(r=-0.195$, $\mathrm{p}=0.042)$. Fasting satiety was negatively correlated with fasting hunger $(\mathrm{r}=-0.508$, $\mathrm{p}<0.001)$ and positively correlated with dietary restraint $(\mathrm{r}=0.274, \mathrm{p}=0.004)$. In addition, dietary disinhibition was positively correlated with both dietary restraint $(r=0.265, p=0.005)$ and with TFEQ hunger $(r=0.621, p<0.001)$

Subjects with BMIs above the median had significantly greater disinhibition (6.5 \pm 3.1 vs. $4.8 \pm 3.1, p=0.005)$ compared to those with BMIs below the median. As shown in Table 3, subjects with a higher fitness status reported significantly lower fasting satiety $(31.4 \pm 22.3$ vs. $36.8 \pm 22.2, p=0.022)$, greater desire to eat $(53.3 \pm 17.5$ vs. $45.5 \pm 20.5, \mathrm{p}=0.037)$, and less dietary restraint $(7.8 \pm 5.2$ vs. $11.3 \pm 5.4, \mathrm{p}=0.001)$ compared to subjects with a lower fitness status. Ghrelin and appetite were not significantly related at single time point measures $(t=0,30 \mathrm{~min})$ and this relationship 
was not modified by cardiorespiratory fitness, BMI, waist circumference, blood glucose or insulin.

Relationships among BMI, waist circumference, \% body fat, insulin and ghrelin BMI was highly correlated with waist circumference $(r=0.836, p<0.001)$. Fasting ghrelin was negatively correlated with BMI $(r=-.290, p=0.005)$, waist circumference $(r=-0.298, p=0.004)$ and insulin $(r=-0.324, p=0.012)$. The relationship between fasting ghrelin and BMI was no longer significant $(p=0.455)$ after controlling for waist circumference. Controlling for blood glucose and insulin did not modify the relationship between BMI and fasting ghrelin. In the fed state, controlling for waist circumference, blood glucose, and insulin did not have an effect on the relationship between BMI and ghrelin. In addition, ANCOVA revealed that differences in fasting ghrelin between BMI groups were no longer significant after controlling for waist circumference, insulin, and blood glucose. Significant differences remained, however, in the fed state even after controlling for these variables. Percent body fat $(n=17)$ was not significantly related to fasting ghrelin $(\mathrm{p}=0.378)$ or fed ghrelin $(\mathrm{p}=0.279)$. Also, $\%$ body fat did not modify the relationship between ghrelin and appetite in the fasting or fed state.

\section{Predictors of fasting ghrelin}

Three models were developed using the variables that were significantly correlated with ghrelin to predict ghrelin levels. The most significant model $(\mathrm{p}<0.001)$ 
was using $\mathrm{BMI}$ and $\mathrm{VO}_{2} \max$ to predict fasting ghrelin. Models are presented in Table

4. 


\section{DISCUSSION}

The results indicate that there is a significant inverse relationship between both $\mathrm{BMI}$ and ghrelin and between $\mathrm{VO}_{2} \max$ and ghrelin in the fed and fasting state. The appetite findings suggest that there are also links among eating behaviors, appetite and both $\mathrm{BMI}$ and $\mathrm{VO}_{2}$ max. Subjects with BMIs above the median had significantly higher disinhibition scores compared to those with BMIs below the median. More fit subjects reported significantly lower fasting satiety, greater desire to eat, and less dietary restraint compared to less fit subjects.

The finding that BMI is negatively associated with ghrelin is in agreement with previous studies $[29,30]$. Similarly, negative relationships between ghrelin and waist circumference [29] and insulin [30] have previously been reported. The relationship between fasting ghrelin and BMI was no longer significant after statistical control for waist circumference. Waist circumference was slightly more correlated with ghrelin than BMI was. In addition, waist circumference and BMI were highly correlated $(r=0.836, p<0.001)$. This is similarly reported in the literature $(r>0.8$ in most studies) [31]. This is useful for future studies and suggests that BMI and waist circumference may be similar indexes of body composition [31].

The significant negative association that was found between $\mathrm{VO}_{2} \mathrm{max}$ and ghrelin was inconsistent with our hypotheses. It was counterintuitive that the associations between ghrelin and $\mathrm{BMI}$ and ghrelin and $\mathrm{VO}_{2} \max$ were both negative. It was hypothesized that the more fit individuals would have higher ghrelin levels. Previous research has indicated that ghrelin increases in response to a negative energy balance $[11,32]$. The literature on the effects of short term exercise on ghrelin is 
inconsistent. Most studies failed to find an effect of exercise on ghrelin levels [12, 3336] but two acute exercise studies have reported increases in ghrelin immediately following exercise $[13,14]$. The conflicting results in differences in protocols make it difficult to reach a consensus.

Research on chronic exercise, however, suggests that ghrelin levels rise from long term exercise interventions $[11,16]$. These findings are complicated by the fact that weight loss also occurred along with the increases in ghrelin, making it difficult to determine if the increases were due to weight loss or to physical activity itself. Weight loss is known to result in increased ghrelin levels [3, 32]. These increases are commensurate with the amount of weight lost [11]. There is some evidence that there may not be an independent effect of exercise on ghrelin apart from weight loss. A study that included a weight stable group found that three months of exercise training had no effect on ghrelin levels in the absence of weight loss [10].

The reason for the negative correlation between ghrelin and $\mathrm{VO}_{2} \max$ is unknown. Other studies that have analyzed $\mathrm{VO}_{2} \mathrm{max}$ and ghrelin are inconclusive. An aerobic exercise intervention involving 173 sedentary, overweight postmenopausal women that compared changes in ghrelin levels to changes in fitness levels (changes in $\mathrm{VO}_{2} \mathrm{max}$ ) from baseline to 12 months found a non-significant negative association between ghrelin and fitness level [11]. Another study conducted on 65 normal weight females found a non-significant positive relationship between fasting ghrelin and $\mathrm{VO}_{2} \max [8]$. The authors also found significant negative associations between ghrelin and RMR and TEF independent of fat mass and fat free mass. A more recent study found that ghrelin was negatively associated with RMR in non-obese women 
independent of body weight [9]. The authors suggested that ghrelin may be regulated by voluntary long-term behavior modification that increases RMR such as aerobic and resistance training [37]. This hypothesis would be consistent with the negative association found between fitness status and ghrelin in our study.

Significant differences in appetite and eating behavior were observed between BMI and fitness categories. Subjects with a higher BMI had greater disinhibition compared to subjects with a lower BMI. This finding was consistent with the literature [38]. Disinhibition is positively correlated with both BMI and obesity. It is also predictive of less successful weight loss attempts, weight regain, and low physical activity [38]. BMI has also been previously associated with dietary restraint $[39,40]$. A significant positive correlation was found between BMI and dietary restraint in our study but there were no significant differences in dietary restraint between BMI groupings.

Subjects with a higher fitness status had significantly lower fasting satiety, greater desire to eat and less dietary restraint. These findings are interesting from a behavioral standpoint. There is a widespread belief that the energy expended from exercise can offset the consumption of more energy dense foods [41]. More fit individuals may be more likely to adopt less stringent diets due to the perception that the additional calories consumed will be expended during exercise. This perception could potentially lead to weight gain in individuals engaging in minimal exercise who feel that they do not have to be as conscious of their energy intake. Alternatively, more fit individuals might not need to restrain their energy intake to regulate body weight. 
Further research should be conducted to determine if lower dietary restraint corresponds to an increase in energy intake in fit individuals.

No significant relationship was found between percent body fat and ghrelin. Previous research reported that ghrelin was negatively correlated with both percent body fat and fat mass [42]. However, in our analysis, since percent body fat data were only available for 17 of the 109 subjects it was difficult to draw conclusions based on this small sub-sample. It would be interesting to examine how percent body fat modifies relationships between ghrelin and appetite on a larger scale.

This study failed to find a significant difference in either fasting or postprandial ghrelin between high and low fitness categories. Also, there was no association found between ghrelin and subjective ratings of appetite. Previous studies have also failed to find an association $[43,44]$. This may be due to the difficulty in finding relationships between plasma ghrelin concentrations and single time point measures of appetite. This also holds true for single time point measures of other biomarkers of satiety [45].

The conclusions are limited by several factors. First, the gender distribution was unbalanced. Males have an inherently greater $\mathrm{VO}_{2} \max$. To account for the gender differences in $\mathrm{VO}_{2} \mathrm{max}$, the sample was grouped into fitness categories according to ACSM gender-specific cutoffs. Most other studies only include one gender. The estimation instead of the direct measurement of $\mathrm{VO}_{2} \max$ was another limitation. Also, there were missing data from the blood draws resulting in 94 subjects with fasting ghrelin values, 69 subjects with postprandial ghrelin values, and 60 subjects with fasting and postprandial insulin values. Another limitation may be that there were 
relatively few subjects with a high $\mathrm{VO}_{2} \max$ and a high BMI. In addition, because this was a secondary data analysis there were differences in experimental protocols between the two studies. For example, the test meals that were provided in each study following fasting measures, were standardized but differed in composition. In the GARF study, participants consumed a breakfast shake that contained $68.3 \%$ carbohydrate, $16.7 \%$ protein, $15 \%$ fat and provided $25 \%$ of each participant's estimated resting energy expenditure as calculated by the WHO equation (males $=(15.3$ $x w t)+679$, females $=(14.7 x w t)+746)($ WHO, 1985). The average kilocalorie content of the shake was $448.1 \mathrm{kcal}$ for males and $347.9 \mathrm{kcal}$ for females. In the GRAIN study, the refined grain test meal that was used in this analysis consisted of corn chex and puffed rice cereal with milk and white toast with strawberry jam. This test meal provided $71 \%$ carbohydrate, $15 \%$ fat, $14 \%$ protein and provided $427.2 \mathrm{kcal}$. Although the total kilocalories and macronutrient composition of the test meals were similar, the perception of satiety may have been altered due to the fact that one test meal was a shake and one was a solid meal.

The strength of the relationships that were found between BMI and ghrelin and between $\mathrm{VO}_{2} \max$ and ghrelin were evidenced by multiple regression analysis. The model including $\mathrm{BMI}$ and $\mathrm{VO}_{2} \max$ as the only predictors of fasting ghrelin proved to be the most significant model. This supports the correlation results.

This study contributes to the scientific literature because it is the largest single analysis to our knowledge that examined relationships of both $\mathrm{BMI}$ and $\mathrm{VO}_{2} \mathrm{max}$ to both fasting and fed ghrelin. Although many of the variables that were included in this analysis were previously studied in relation to ghrelin, the relationships among BMI, 
$\mathrm{VO}_{2} \max$, ghrelin and appetite have not been directly compared. In addition, the inclusion of both genders and the use of both fasting and postprandial ghrelin data were unique features of this study. The nature of the secondary data analysis also allowed for a larger sample size $(n=109)$ compared to other studies in this field. These findings confirm previous relationships reported between BMI and ghrelin, subjective appetite and eating behaviors and corroborate lack of associations between single-point time measures of ghrelin and appetite. Additionally, results indicate that cardiorespiratory fitness is related to circulating ghrelin levels, subjective appetite, and degree of dietary restraint. Further study is needed to determine the nature of these relationships. 


\section{REFERENCES}

1. Kopelman, P.G., Obesity as a medical problem. Nature, 2000. 404(6778): p. 635-43.

2. Cummings, D.E., Ghrelin and the short- and long-term regulation of appetite and body weight. Physiol Behav, 2006. 89(1): p. 71-84.

3. Cummings, D.E., et al., A preprandial rise in plasma ghrelin levels suggests a role in meal initiation in humans. Diabetes, 2001. 50(8): p. 1714-9.

4. Tschop, M., D.L. Smiley, and M.L. Heiman, Ghrelin induces adiposity in rodents. Nature, 2000. 407(6806): p. 908-13.

5. Nakazato, M., et al., A role for ghrelin in the central regulation of feeding. Nature, 2001. 409(6817): p. 194-8.

6. Wren, A.M., et al., Ghrelin causes hyperphagia and obesity in rats. Diabetes, 2001. 50(11): p. 2540-7.

7. Druce, M.R., et al., Ghrelin increases food intake in obese as well as lean subjects. Int J Obes (Lond), 2005. 29(9): p. 1130-6.

8. St-Pierre, D.H., et al., Relationship between ghrelin and energy expenditure in healthy young women. J Clin Endocrinol Metab, 2004. 89(12): p. 5993-7.

9. St-Pierre, D.H., et al., Lifestyle behaviours and components of energy balance as independent predictors of ghrelin and adiponectin in young non-obese women. Diabetes Metab, 2006. 32(2): p. 131-9.

10. Leidy, H.J., et al., Circulating ghrelin is sensitive to changes in body weight during a diet and exercise program in normal-weight young women. J Clin Endocrinol Metab, 2004. 89(6): p. 2659-64. 
11. Foster-Schubert, K.E., et al., Human plasma ghrelin levels increase during a one-year exercise program. J Clin Endocrinol Metab, 2005. 90(2): p. 820-5.

12. Schmidt, A., et al., Acute exercise has no effect on ghrelin plasma concentrations. Horm Metab Res, 2004. 36(3): p. 174-7.

13. Jurimae, J., T. Jurimae, and P. Purge, Plasma ghrelin is altered after maximal exercise in elite male rowers. Exp Biol Med (Maywood), 2007. 232(7): p. 9049.

14. Erdmann, J., et al., Plasma ghrelin levels during exercise - effects of intensity and duration. Regul Pept, 2007. 143(1-3): p. 127-35.

15. George, V.A. and A. Morganstein, Effect of moderate intensity exercise on acute energy intake in normal and overweight females. Appetite, 2003. 40(1): p. 43-6.

16. Leidy, H.J., et al., Twenty-four-hour ghrelin is elevated after calorie restriction and exercise training in non-obese women. Obesity (Silver Spring), 2007. 15(2): p. 446-55.

17. Broom, D.R., et al., Exercise-induced suppression of acylated ghrelin in humans. J Appl Physiol, 2007. 102(6): p. 2165-71.

18. King, N.A., A. Tremblay, and J.E. Blundell, Effects of exercise on appetite control: implications for energy balance. Med Sci Sports Exerc, 1997. 29(8): p. $1076-89$.

19. Blundell, J.E., et al., Cross talk between physical activity and appetite control: does physical activity stimulate appetite? Proc Nutr Soc, 2003. 62(3): p. 65161. 
20. Harris, C.L. and V.A. George, The impact of dietary restraint and moderateintensity exercise on post-exercise energy intake in sedentary males. Eat Behav, 2008. 9(4): p. 415-22.

21. Keim, N.L., et al., Effect of exercise and dietary restraint on energy intake of reduced-obese women. Appetite, 1996. 26(1): p. 55-70.

22. King, N.A., What processes are involved in the appetite response to moderate increases in exercise-induced energy expenditure? Proc Nutr Soc, 1999. 58(1): p. 107-13.

23. McArdle, W.D., et al., Reliability and interrelationships between maximal oxygen intake, physical work capacity and step-test scores in college women. Med Sci Sports, 1972. 4(4): p. 182-6.

24. Craig, C.L., et al., International physical activity questionnaire: 12-country reliability and validity. Med Sci Sports Exerc, 2003. 35(8): p. 1381-95.

25. Flint, A., et al., Reproducibility, power and validity of visual analogue scales in assessment of appetite sensations in single test meal studies. Int J Obes Relat Metab Disord, 2000. 24(1): p. 38-48.

26. Stunkard, A.J. and S. Messick, The three-factor eating questionnaire to measure dietary restraint, disinhibition and hunger. J Psychosom Res, 1985. 29(1): p. 71-83.

27. Siri, W., Body composition from fluid spaces and density. In: Techniques for measuring body composition., ed. H.A. Brozek J. 1961, Washington, DC: National Academy of Sciences. 223-224 
28. Fields, D.A., M.I. Goran, and M.A. McCrory, Body-composition assessment via air-displacement plethysmography in adults and children: a review. Am J Clin Nutr, 2002. 75(3): p. 453-67.

29. Monti, V., et al., Relationship of ghrelin and leptin hormones with body mass index and waist circumference in a random sample of adults. J Am Diet Assoc, 2006. 106(6): p. 822-8; quiz 829-30.

30. Morpurgo, P.S., et al., Ghrelin secretion in severely obese subjects before and after a 3-week integrated body mass reduction program. J Endocrinol Invest, 2003. 26(8): p. 723-7.

31. Moore, S.C., Waist versus weight: which matters more for mortality? Am J Clin Nutr, 2009. 89(4): p. 1003-4.

32. Hansen, T.K., et al., Weight loss increases circulating levels of ghrelin in human obesity. Clin Endocrinol (Oxf), 2002. 56(2): p. 203-6.

33. Burns, S.F., et al., A single session of treadmill running has no effect on plasma total ghrelin concentrations. J Sports Sci, 2007. 25(6): p. 635-42.

34. Dall, R., et al., Plasma ghrelin levels during exercise in healthy subjects and in growth hormone-deficient patients. Eur J Endocrinol, 2002. 147(1): p. 65-70.

35. Kraemer, R.R., et al., Rigorous running increases growth hormone and insulin-like growth factor-I without altering ghrelin. Exp Biol Med (Maywood), 2004. 229(3): p. 240-6.

36. Jurimae, J., et al., Plasma ghrelin responses to acute sculling exercises in elite male rowers. Eur J Appl Physiol, 2007.99(5): p. 467-74. 
37. Speakman, J.R. and C. Selman, Physical activity and resting metabolic rate. Proc Nutr Soc, 2003. 62(3): p. 621-34.

38. Bryant, E.J., N.A. King, and J.E. Blundell, Disinhibition: its effects on appetite and weight regulation. Obes Rev, 2008. 9(5): p. 409-19.

39. de Lauzon-Guillain, B., Basdevant, A., Romon, M., Karlsson, J., Borys, J.M., Charles, M.A., The FLVS Study Group Is restrained eating a risk factor for weight gain in a general population? Am J Clin Nutr, 2006. 83: p. 132-138.

40. Lluch, A., et al., Dietary intakes, eating style and overweight in the Stanislas Family Study. Int J Obes Relat Metab Disord, 2000. 24(11): p. 1493-9.

41. Hubert, P., N.A. King, and J.E. Blundell, Uncoupling the effects of energy expenditure and energy intake: appetite response to short-term energy deficit induced by meal omission and physical activity. Appetite, 1998. 31(1): p. 9-19.

42. Tschop, M., et al., Circulating ghrelin levels are decreased in human obesity. Diabetes, 2001. 50(4): p. 707-9.

43. Blom, W.A., et al., Effect of a high-protein breakfast on the postprandial ghrelin response. Am J Clin Nutr, 2006. 83(2): p. 211-20.

44. Erdmann, J., et al., Postprandial response of plasma ghrelin levels to various test meals in relation to food intake, plasma insulin, and glucose. J Clin Endocrinol Metab, 2004. 89(6): p. 3048-54.

45. de Graaf, C., et al., Biomarkers of satiation and satiety. Am J Clin Nutr, 2004. 79(6): p. 946-61. 
Table 1: Subject characteristics

* $\mathrm{VO}_{2}$ max was estimated by the Queen's College Step Test

**Ghrelin was measured after a 10 hour overnight fast and 30 minutes after a standardized meal

\begin{tabular}{|l|c|c|}
\hline Subject Characteristics & $\mathbf{n}$ & Mean \pm SD \\
\hline Age (years) & 109 & $19.4 \pm 2.1$ \\
\hline BMl $\left(\mathrm{kg} / \mathrm{m}^{2}\right)$ & 109 & $22.9 \pm 3.9$ \\
\hline Estimated $\mathrm{VO}_{2} \max (\mathrm{ml} / \mathrm{kg} / \mathrm{min})^{*}$ & 108 & $40.3 \pm 5.6$ \\
\hline Waist circumference $(\mathrm{cm})$ & 109 & $79.6 \pm 10.0$ \\
\hline Fasting ghrelin $(\mathrm{pcg} / \mathrm{mL})^{* *}$ & 94 & $745 \pm 256$ \\
\hline Fed ghrelin $(\mathrm{pcg} / \mathrm{mL})^{* *}$ & 69 & $634 \pm 204$ \\
\hline
\end{tabular}


Table 2: Mean ghrelin levels by BMI category

Below median

Above median

$P$ value

\begin{tabular}{lccccc} 
& & & & & \\
& $\mathrm{n}$ & mean & $\mathrm{n}$ & mean & \\
\hline Fasting ghrelin, pg/mL & 45 & $802 \pm 266$ & 49 & $692 \pm 238$ & 0.037 \\
Fed ghrelin, pg/mL & 30 & $710 \pm 226$ & 39 & $575 \pm 164$ & 0.005
\end{tabular}


Table 3: Mean appetite scores by fitness category

*VAS range: 0-100

**TFEQ ranges: restraint 0-21

disinhibition 0-13

hunger $0-13$

Cardiorespiratory Fitness Category

\begin{tabular}{ccc} 
Lower Fit $(n=60)$ & Higher Fit $(n=48)$ & P value \\
\hline $46.58 \pm 25.98$ & $51.93 \pm 24.92$ & 0.281 \\
$41.10 \pm 21.22$ & $31.35 \pm 22.34$ & 0.022 \\
$45.48 \pm 20.48$ & $53.33 \pm 17.47$ & 0.037 \\
$11.28 \pm 5.40$ & $7.81 \pm 5.16$ & 0.001 \\
$5.85 \pm 3.19$ & $5.46 \pm 3.27$ & 0.532 \\
$5.52 \pm 2.90$ & $5.77 \pm 3.01$ & 0.657
\end{tabular}

VAS fasting hunger*

VAS fasting satiety*

VAS fasting desire to eat*

TFEQ Restraint ${ }^{\star *}$

TFEQ Disinhibition**

TFEQ Hunger**

$5.77 \pm 3.01$

0.657 
Table 4: Fasting ghrelin prediction equations

\begin{tabular}{|c|c|c|c|c|c|c|c|}
\hline & Predictor (s) & $B$ & $\beta$ & $t$ & $p$ & $\mathbf{R}$ & $\mathrm{R}^{2}$ \\
\hline \multicolumn{8}{|l|}{ Equation 1} \\
\hline & Constant & 1302.505 & & 5.148 & 0.000 & & \\
\hline & $W C(\mathrm{~cm})$ & -5.954 & -0.231 & -1.836 & 0.072 & & \\
\hline & Insulin (mU/L) & -9.202 & -0.265 & -2.108 & 0.039 & 0.393 & 0.155 \\
\hline \multicolumn{8}{|l|}{ Equation 2} \\
\hline & Constant & 1211.412 & & 6.555 & 0.000 & & \\
\hline & $\mathrm{BMI}\left(\mathrm{kg} / \mathrm{m}^{2}\right)$ & -16.366 & -0.250 & -2.045 & 0.045 & & \\
\hline & Insulin (mU/L) & -10.015 & -0.289 & -2.363 & 0.022 & 0.407 & 0.166 \\
\hline \multicolumn{8}{|l|}{ Equation 3} \\
\hline & Constant & 1829.320 & & 7.725 & 0.000 & & \\
\hline & $\mathrm{BMI}\left(\mathrm{kg} / \mathrm{m}^{2}\right)$ & -20.630 & -0.315 & -3.313 & 0.001 & & \\
\hline & $\mathrm{VO}_{2} \max (\mathrm{ml} / \mathrm{kg} / \mathrm{min})$ & -15.148 & -0.328 & -3.455 & 0.001 & 0.438 & 0.191 \\
\hline
\end{tabular}




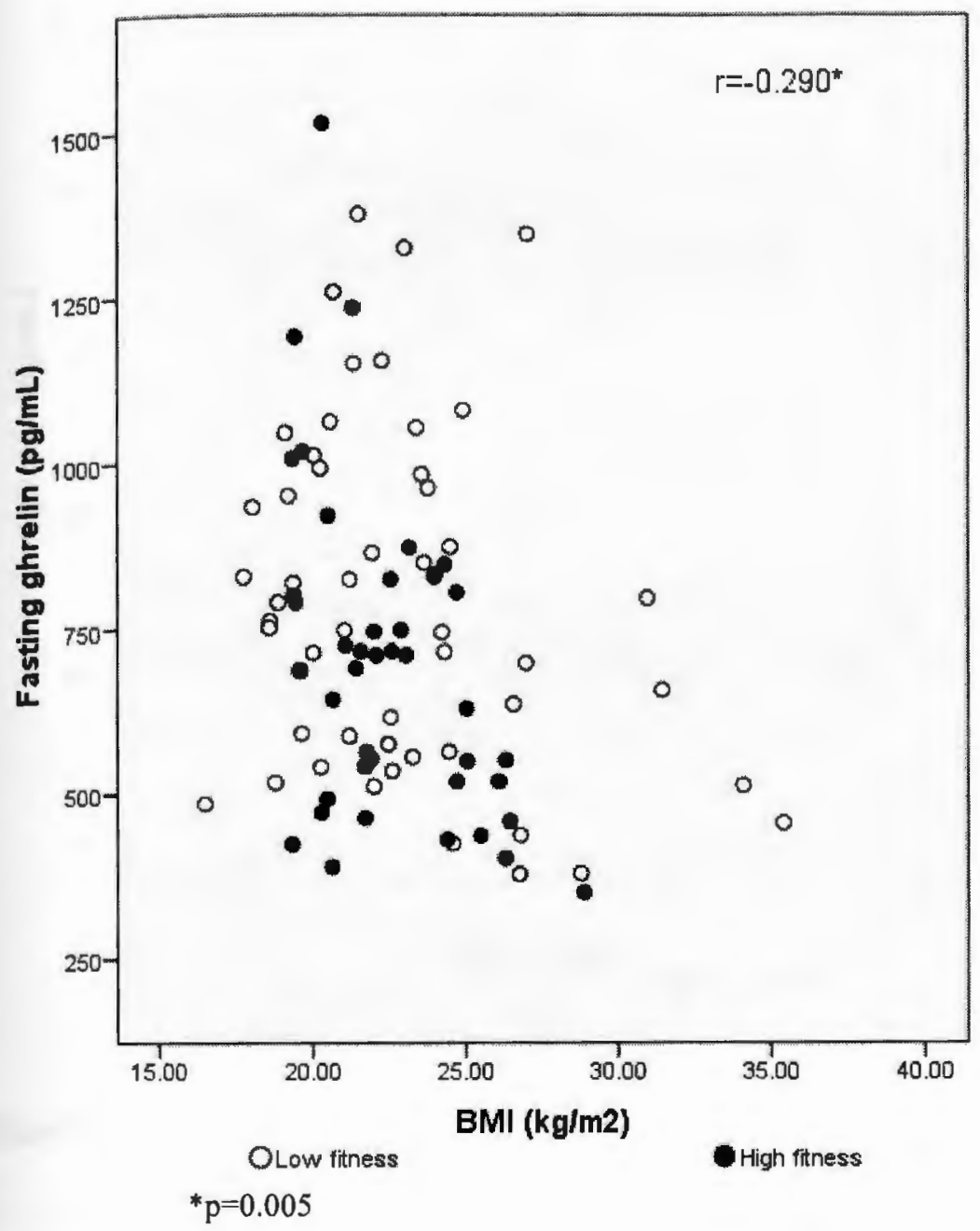

Figure 1: Relationship between fasting ghrelin and BMI 


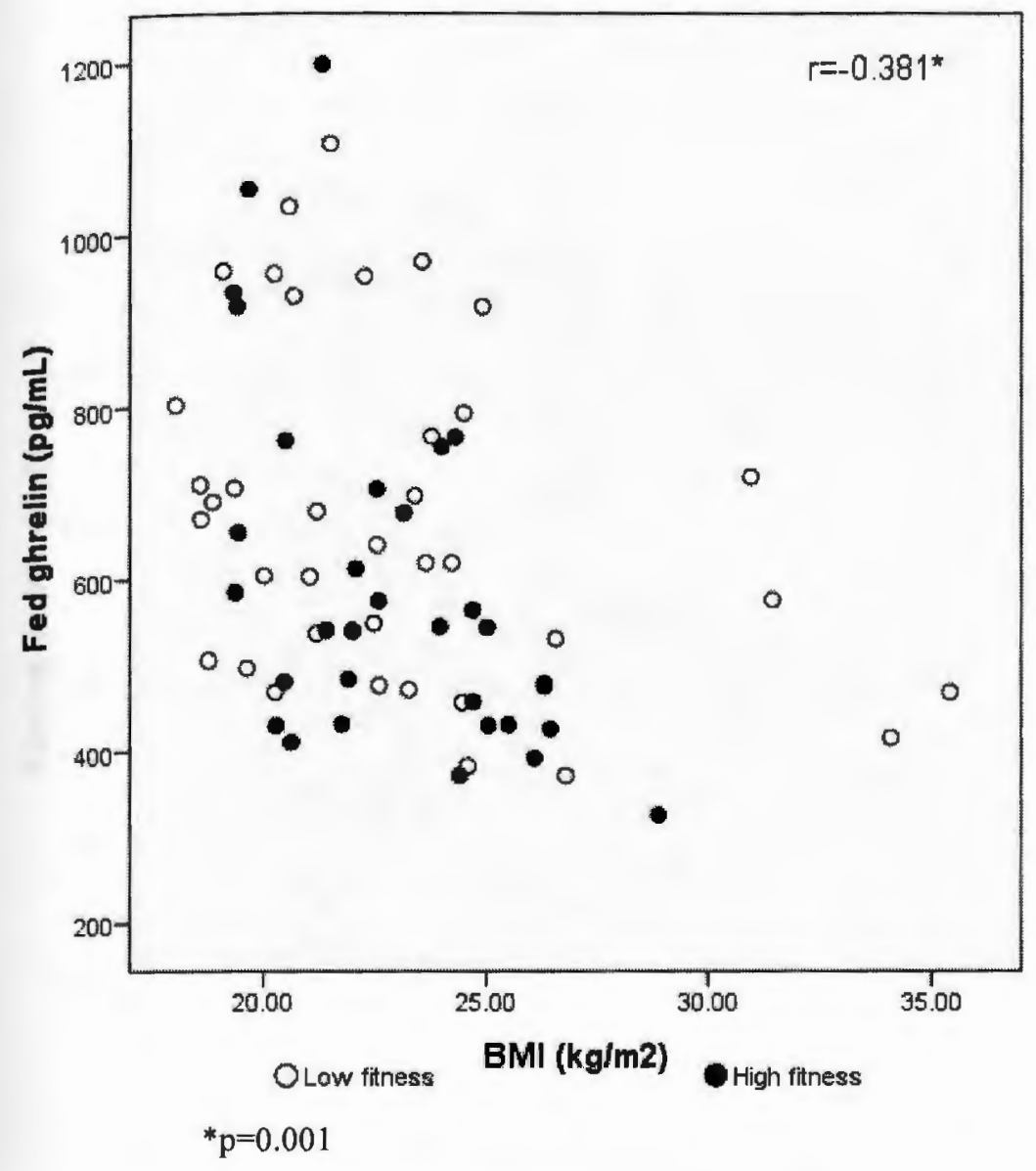

Figure 2: Relationship between fed ghrelin and BMI 


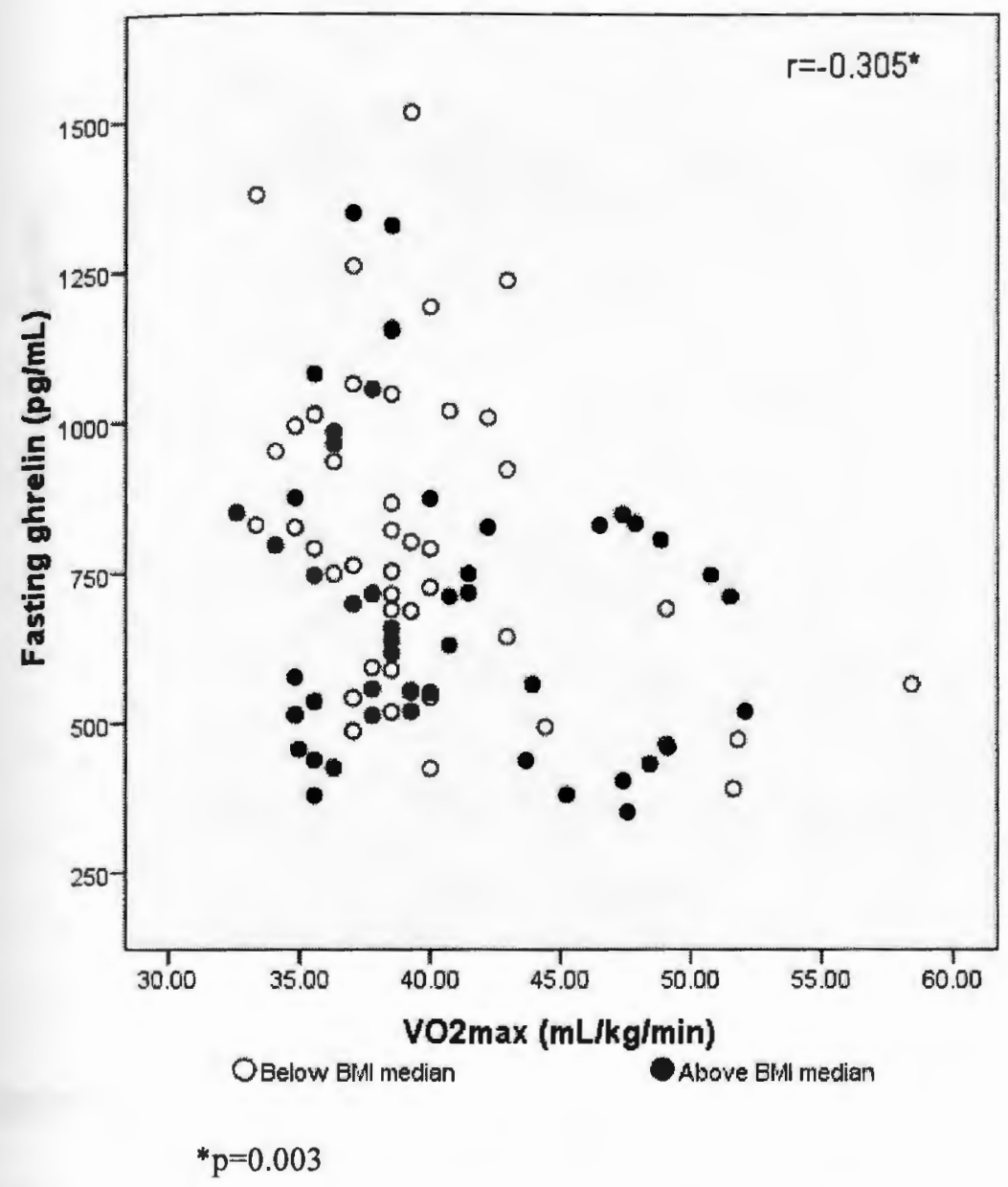

Figure 3: Relationship between fasting ghrelin and estimated cardiorespiratory fitness 


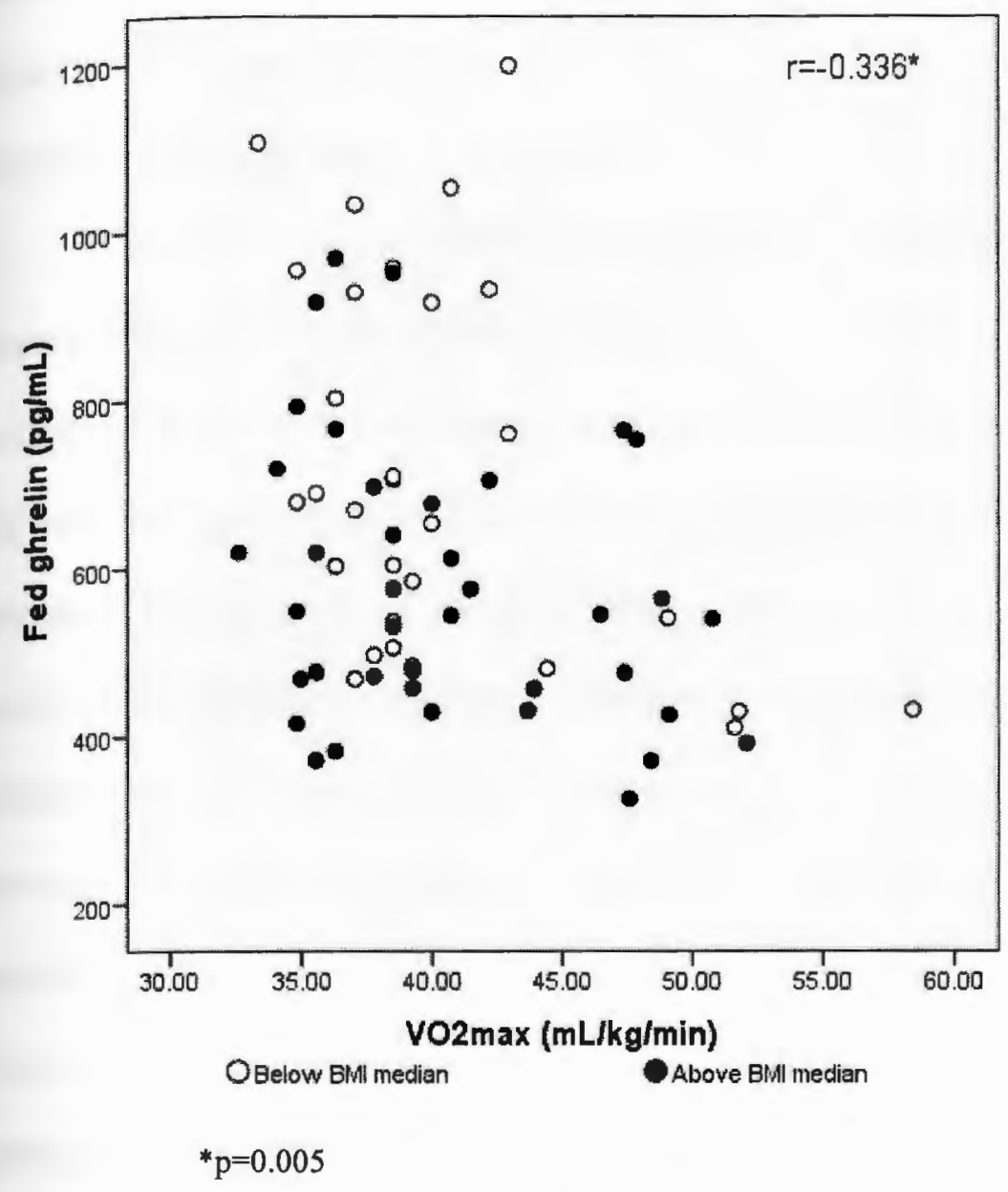

Figure 4: Relationship between fed ghrelin and estimated cardiorespiratory fitness 


\section{APPENDIX A}

\section{Literature Review}

\section{Ghrelin and Energy Balance}

Ghrelin is a recently discovered hormone that regulates energy balance $[1,2]$. Since its discovery in 1999, it has piqued much interest in the field of energy metabolism. Studies have indicated that ghrelin plays a pivotal role in both short term and long term energy balance [3]. Ghrelin is a hyperphagic hormone secreted by the stomach that participates in meal initiation [3]. Research also suggests that ghrelin is involved in long term energy balance. Ghrelin is associated with energy storage. Studies have found that ghrelin levels are elevated in individuals with anorexia nervosa [4] and levels are decreased in obese individuals [5]. This indicates that ghrelin is downregulated in response to excess energy stores. Ghrelin levels return to normal when a healthy body weight is achieved [6]. Hansen's research that measured fasting ghrelin in response to weight loss in obese subjects not only found that fasting ghrelin concentrations increased with weight loss but also found that this increase was positively correlated with the extent of weight loss [5]. In a six month diet program for weight loss, Cummings et al. found a 24 percent increase in the area under the curve for the 24-hour ghrelin profile with a diet induced weight loss of 17 percent [7]. This is consistent with the hypothesis that ghrelin has a role in the long term regulation of body weight [7]. A negative energy balance or weight loss threshold for increasing ghrelin, however, has yet to be determined [8]. 
Ghrelin and Appetite

Ghrelin stimulates appetite by acting on the arcuate nucleus in the hypothalamus. This region is responsible for controlling food intake [9]. Ghrelin plays an important role as a short term regulator of appetite through its involvement in meal initiation. Studies on rodents indicate that ghrelin infusion promotes weight gain by increasing food intake and decreasing energy expenditure and fat catabolism [10-12]. Intravenous infusion of ghrelin in humans increased food intake in both lean and obese subjects [13]. Endogenous ghrelin levels rise before meals to sufficient levels to stimulate appetite [3]. Postprandial ghrelin levels are quickly suppressed by nutrient ingestion [14]. This is evidenced by twenty-four hour plasma profiles that show these preprandial increases in ghrelin and postprandial decreases in ghrelin with every meal $[14,15]$.

A study that analyzed the short term effects of energy restriction on total fasting and postprandial ghrelin reported no significant changes in ghrelin after the four day energy restriction [16]. There were no associations found between total ghrelin and appetite scores. This suggests that ghrelin does not have an immediate effect on appetite in a typical hypocaloric dietary regimen.

\section{Ghrelin Biochemistry}

Ghrelin is synthesized predominantly by the stomach [17]. The fundus synthesizes approximately ten times more ghrelin per gram of tissue than other production sites including the duodenum and other parts of the small intestine [18]. Gastrectomy and small bowel resections have indicated that approximately $2 / 3$ of 
circulating ghrelin is secreted by the stomach with the rest being secreted by the small intestine [19]. Ghrelin is a peptide containing 28 amino acids. It undergoes posttranslational modification that involves the acylation of the serine- 3 residue. The serine residue is covalently attached to a medium-chain fatty acid by an ester bond. This acylation is necessary for ghrelin to bind and activate its receptor, the growth hormone secretagogue receptor (GHS-R) [9]. As a result, most of ghrelin's physiological roles are associated with its acylated form, commonly referred to as active ghrelin. Studies in mice lacking the GHS-R gene have suggested that this receptor is responsible for the orexigenic effects of ghrelin [20]. Ghrelin also exists, however, in another isoform, des-acyl ghrelin, which is suggested to play important roles in glucose and insulin metabolism [21-23] and in adipogenesis [24]. Research is being conducted to identify alternate ghrelin receptors that interact with the desacylated form [2].

\section{Ghrelin and Exercise}

Research has been devoted to examining the effects of exercise on ghrelin due to ghrelin's role in chronic energy balance. Since exercise and ghrelin both affect energy balance, studies have been performed to determine if a relationship exists between the two. Ghrelin levels are increased in states of negative energy balance [5]. This increase may be part of an adaptive response to counteract a negative energy balance [25]. As a result, it has been hypothesized that the energy expenditure resulting from exercise may have an effect on ghrelin. Both short term studies [26-28] and long term studies $[6,25]$ have been performed to examine the effects of exercise 
on ghrelin. Most of the studies examining acute exercise on ghrelin levels have failed to find an effect on ghrelin levels during or shortly after exercise. One study involving treadmill exercise at $50 \%, 70 \%$, and $90 \%$ of $\mathrm{VO}_{2} \max$ found no changes in ghrelin at any of the three intensities [26]. No changes in ghrelin were observed in a similar study involving a one hour treadmill bout at $73 \%$ of $\mathrm{VO}_{2} \max$ compared to the control condition [29]. Other studies produced conflicting results. In one study, ghrelin was suppressed during both aerobic and resistance exercise conditions [30]. In contrast, another study reported a significant increase in ghrelin immediately after maximal exercise in male rowers [27]. This effect, however, was short lived as ghrelin levels returned to baseline after 30 minutes [27]. In a cycling study, ghrelin levels rose during low intensity exercise but did not rise with high intensity exercise [28]. The conflicting results and differences in protocols make it difficult for a consensus to be reached.

The literature on the effects of chronic exercise on ghrelin levels, however, is more clear. Previous studies have shown that weight loss resulting from reduced calorie intake increases ghrelin levels $[5,15]$. This finding led researchers to examine whether an exercise-induced calorie deficit would lead to similar results. Multiple studies have examined changes in ghrelin with chronic exercise. A three month diet and exercise intervention produced significant increases in baseline ghrelin, lunch peak, dinner peak, nocturnal rise, and nocturnal peak [31]. A one-year aerobic exercise intervention found that exercise-induced weight loss, in the absence of reduced food intake, was associated with significant increases in ghrelin [25]. These increases in ghrelin were commensurate with the amount of weight lost [25]. In the exercise group, 
however, ghrelin levels did not increase in those who did not lose weight or lost a mild amount of weight $(0.5-3 \mathrm{~kg})$ suggesting that there was no independent effect of exercise.

Another three month exercise intervention reported a significant increase in ghrelin in the weight loss group compared to the controls and the weight stable group [6]. By including a weight stable exercise group, this study was able to demonstrate that exercise training in the absence of weight loss had no effect on ghrelin. These studies add to the body of literature that suggests that ghrelin is a long-term regulator of energy balance. However, since many of these studies include weight loss as a function of the exercise protocols, it is difficult to determine if changes in ghrelin are related to weight loss or to physical activity itself.

Ghrelin, Fitness, and BMI

The results of studies on exercise and ghrelin raise important questions about the relationship between ghrelin, fitness status, and BMI. Ghrelin is associated with key components of energy balance [6]. For instance, ghrelin is negatively correlated with percentage of body fat, fat mass [14], waist circumference [32], BMI [32, 33], body weight, insulin and leptin [33]. The one year exercise induced weight loss intervention conducted by Foster-Schubert found that as body composition variables changed, the magnitude of the increase in ghrelin was correlated with the magnitude of the decrease in body weight, BMI, waist circumference, and total fat mass. The magnitude of the increase in ghrelin was not significantly correlated with the changes in lean body mass, intraabdominal fat, subcutaneous fat, energy intake, $\mathrm{VO}_{2} \mathrm{max}$, 
leptin or insulin [25]. One study found lower resting metabolic rate (RMR) to be associated with higher ghrelin levels in 63 young non-obese women [34]. Another study involving 65 non-obese women found that ghrelin was negatively correlated with RMR and thermic effect of food (TEF) independent of variations in body composition, insulin levels and daily energy intake [1]. In contrast to previous studies, however, no significant correlations were found between ghrelin and percent body fat, total fat mass, fat-free mass, physical activity, $\mathrm{VO}_{2} \max$ or dietary disinhibition, dietary restraint, or feelings of general hunger [1]. Although no significant associations were found between ghrelin and $\mathrm{VO}_{2} \max$ by St-Pierre et al., this area deserves more attention since the lack of significant findings could be attributed to the homogenous sample. The subject population consisted of 65 normal weight females. Another limitation may have been the measurement of only fasting ghrelin. Our current study included appetite measures, body composition measures, and fitness measures $\left(\mathrm{VO}_{2} \mathrm{max}\right)$ in relation to ghrelin and also included both genders and both fasting and fed ghrelin. These features distinguish it from previous studies in this area.

\section{Ghrelin and Gender}

A study examining plasma ghrelin and its relation to body composition reported that there were gender differences in the nature of these associations. Plasma ghrelin levels were inversely associated with fat mass measures in both males and females but there were gender differences in which of these body composition variables were related to ghrelin. For example, in males, plasma ghrelin was inversely correlated with abdominal fat mass and fat distribution index (calculated as the 
trunk/leg fat mass ratio from dual energy $\mathrm{x}$-ray absorptiometry body composition analysis). In females, inverse correlations were found between plasma ghrelin and BMI, total fat mass, and fat mass/lean mass ratio [35].

Since there are fluctuations in appetite with the menstrual cycle some studies have investigated if ghrelin levels also vary throughout the menstrual cycle. One study aimed specifically at abnormal menstrual cycles found that fasting ghrelin levels were at least $85 \%$ higher in women with exercise associated amenorrhea [36]. This supports the role for ghrelin as a metabolic indicator of chronic energy deficient states. In a normal menstrual cycle, however, a recent study reported that there were no significant changes in ghrelin throughout the cycle [37]. This is useful in planning future studies involving female subjects.

Fitness, Appetite, and Energy Intake

The relationship between fitness, appetite and energy intake also warrants further investigation. Appetite plays a central role in the regulation of energy balance [38]. The effects of exercise on appetite and food intake are controversial and depend on the intensity and duration of exercise. Several studies have investigated the effects of acute exercise on appetite and energy intake. There appears to be a weak coupling between energy expenditure and energy intake in the short term [39].

The effects of exercise on appetite and energy intake are influenced by the intensity of exercise performed. High intensity exercise has been shown to suppress hunger in the short term [39]. A study involving cycling at $35 \%$ and $68 \%$ of $\mathrm{VO}_{2} \max$ indicated that hunger ratings were significantly lower in subjects in the highest 
intensity exercise condition compared to those in the resting condition [40]. This hunger suppression did not translate to a reduction in food intake, however. The absence of an effect on food intake has been reported elsewhere [39, 41-43]. This is not surprising given that appetite is mediated by hormonal, psychological, and environmental factors [44]. Low to moderate intensity exercise has not been associated with this suppression [45]. This suggests that the intensity of the exercise has an effect on the extent of appetite and food intake suppression.

Exercise duration also has an effect on appetite and food intake. Erdmann et al. (2007) found that short duration exercise of 30-60 minutes had no effect on hunger/satiety sensations and subsequent food intake[28]. In this same study, a longer duration of exercise of 120 minutes produced an increase in food intake without having an effect on subjective hunger sensations.

Most studies dealing with exercise and hunger suppression have focused on aerobic exercise [8]. Little is known about the effects of resistance exercise on appetite. One recent study conducted by Broom et al. (2009) compared the effects of resistance and aerobic exercise on both hunger and ghrelin levels. Both hunger and ghrelin were significantly suppressed in the aerobic and resistance conditions compared to the control condition. This suppression was observed both during and after exercise until the first test meal ( $t=2$ hours). After the consumption of the test meal, there were no significant differences in hunger between the exercise conditions and the control [30]. The finding that hunger is suppressed immediately after vigorous aerobic exercise (greater than $60 \% \mathrm{VO}_{2} \mathrm{max}$ ) is consistent with previous studies including a prior study conducted by Broom involving running for 60 minutes at $72 \%$ 
$\mathrm{VO}_{2} \max [46]$. The effects of resistance exercise on hunger were new findings. Although resistance exercise was not found to suppress hunger to the same extent as aerobic exercise did, the suppression was still significant compared to the control. This attenuated response may be attributed to the lower energy expenditure along with the intermittent nature of resistance exercise compared to aerobic exercise [30].

Some studies have examined the effects of body weight, exercise and food intake. Non-obese women had lower post-exercise energy intakes after strenuous exercise, whereas obese women showed no change in intake across exercise conditions [41]. A different study reported no significant differences in post-exercise energy intake between obese and lean individuals [47]. However, obese subjects were found to have a decrease in hunger and appetite after exercise but without an accompanying decrease in energy intake [47]. Another study found that energy intake was higher in obese women compared to normal weight women after moderate intensity exercise and on the control day [44]. These results demonstrate the complexity of the relationship between exercise, body weight, appetite, and food intake.

While there is evidence of exercise-induced anorexia in the short term [45], a positive relationship exists between physical activity and energy intake in the long term[48]. It has been suggested that physiological and behavioral adaptations occur in the interim [48]. Short term (1-2 days) and medium term (7-16 days) exercise-induced negative energy balances of up to $4 \mathrm{MJ} / \mathrm{d}$ occur before compensation in energy intake is observed [45]. Beyond this, a compensatory effect takes place and food intake is increased to compensate for an average of approximately $30 \%$ of energy expended in 
physical activity [45]. This compensation is not universally observed. Subjects can be classified as "compensators," those who display increases in energy intake with exercise, or "non-compensators," those who do not show increases in energy intake with exercise [45]. Further research is needed to determine the mechanisms through which this compensation occurs but there is some evidence that body composition plays a role in the extent of this compensation [49]. It has been suggested that fat mass acts as an energy buffer and increases in energy intake are not observed until lean body mass is threatened by the energy deficit created from physical activity [45].

A recent review analyzed the effects of chronic exercise on energy intake, energy balance and body weight [50]. While short to medium term exercise is effective at inducing a negative energy balance, long term exercise unless accompanied by calorie restriction, results in only minor weight loss.

The literature highlights many factors that could be responsible for the lack of a substantial effect of exercise on weight loss. These include both physiological and behavioral adaptations to counteract the new energy balance. Weight loss is associated with a compensatory reduction in total BMR [48] and an increase in ghrelin levels [5-7]. Also, as $\mathrm{VO}_{2}$ max increases with exercise training, a lower energy expenditure is achieved for the same volume of exercise. Energy expenditure from exercise is also reduced with a lower body weight [48].

Behavioral mechanisms such as compensatory increases in energy intake from a less stringent dietary regimen may also counteract the energy deficit created by exercise. This is linked to the popular belief that the energy cost of exercise can offset the consumption of more energy dense foods [51]. Despite these compensations, 
exercise is essential in preventing weight gain or regain in the long term [50]. The role of exercise in weight maintenance is thought to be a result of an improvement in appetite control and a better coupling between energy intake and energy expenditure [50]. One possible explanation for this improvement in appetite control may be linked to an increase in satiety hormones including polypeptide $\mathrm{YY}$, glucagon-like peptide-1 and pancreatic polypeptide with exercise [52]. However, the extent to which changes in ghrelin may play a role in these relationships remains to be elucidated. The increase in these hormones may be responsible for the previously described phenomenon of exercise-induced anorexia.

\section{Eating Behaviors and Appetite Control}

Eating behavior is influenced by a multitude of factors ranging from physiological to cognitive and socio-cultural factors [53]. In order to fully understand eating behavior, it is important to examine both the physiological and nonphysiological factors that affect energy intake. Physiological components of total food intake include hunger, satiation, satiety, and sensory-specific satiety. These factors are regulated by a combination of physical factors including gastric filling, distention, contraction and emptying and metabolic factors including gut peptides, neuropeptides, hormones and the detection of nutrients absorbed into the circulation [38].

At the physiological level, appetite and food intake are regulated by the brain and by hormones from the gastrointestinal tract, pancreas, adrenal glands and adipose tissue. The hypothalamus is involved in the central regulation of appetite and continuously receives neural, metabolic, and endocrine signals from the periphery. 
Specifically, the arcuate nucleus within the hypothalamus contains many of the receptors for hormones and peptides known to be involved in the regulation of energy intake [50].

Traditional physiologic appetite theories focus on the individual's internal state and explain meal initiation by a "hunger drive" that increases proportionately to individual needs and is decreased by food intake [53]. Eating behavior, however, is much more complex than simple depletion-repletion models can explain and nonphysiological factors must be considered. Appetite is influenced by a combination of cognitive, hedonic, psychological, habitual, cultural and social factors [38].

Physiological mechanisms that control food intake can easily be overridden by social and environmental factors.

\section{Dietary Restraint and Disinhibition}

The development of the Three Factor Eating Questionnaire (TFEQ) by Stunkard and Messick in 1985 has led to much research on eating behavior. The TFEQ measures three factors: restraint, disinhibition and hunger. The concept of dietary restraint has dominated the literature due to its relation to eating disorders, weight gain, and weight loss and dieting success [54]. Dietary restraint is a common control mechanism to lose weight or to prevent weight gain. A significant percentage of the population in Western countries consciously limits their food intake as a weight control strategy [55]. Dietary restraint is defined as a self-imposed resistance to the internal and external cues that regulate eating behavior [56]. Excessive restriction may have a counterproductive effect and eventually may lead to weight gain. Dietary 
restraint is frequently associated with disinhibition and can even lead to disordered eating patterns [53].

Restrained eating behavior has also been linked to both metabolic and endocrine abnormalities [55]. A recent study measured the impact of dietary restraint on the plasma levels of different metabolites after the consumption of a standardized test meal in normal weight adults [55]. Restrained eaters were found to have significantly lower fasting insulin levels and lower insulin and glucose levels in the postprandial state. Restrained eaters also had better insulin sensitivity. Previous studies have demonstrated that restrained eaters have a reduced secretion of noradrenaline in the postprandial state [57] and a lower diet-induced thermogenesis [58] and fat oxidation [59] after a meal. The lower plasma insulin observed in restrained eaters is thought to be mediated by the reduced secretion of noradrenaline. Noradrenaline triggers the release of glucose into the bloodstream. Reduced secretion of noradrenaline would therefore result in lower levels of blood glucose in the postprandial state and would require less insulin [55].

A longitudinal study examined cognitive restraint and weight gain in a large sample of normal and overweight adults and adolescents [60]. The findings indicated that restraint was positively correlated with BMI in normal weight but not in overweight subjects. Restrained eating was not predictive of weight gain. However, a high initial BMI was associated with a greater increase in cognitive restraint over the two year period. These findings were in contrast to a previous cross-sectional study performed on restrained eating and weight gain that reported that restrained eating is higher with greater BMI [61]. 
Although most of the literature has focused on restraint, disinhibition also plays an important role in appetite and weight regulation. Disinhibition refers to a tendency towards over-eating. Disinhibition includes over-eating because others are eating, not being able to resist food, eating in response to negative mood states, and over-eating highly palatable foods [62]. Disinhibition is positively correlated with BMI and obesity [62]. It is also predictive of less successful weight loss attempts and of weight regain. In addition, disinhibition is associated with lower self-esteem, poor psychological health, and low physical activity [62].

Relatively little research has directly examined the relationship between disinhibition and physical activity but a few studies have been conducted. One study suggested that women who exercised and had high disinhibition scores increased their energy intakes leading to a positive energy balance [59]. On the other hand, acute exercise was shown to have a beneficial effect on women who had high disinhibition scores by decreasing their motivation to eat and increasing their preference for low-fat foods[54].

\section{Effects of Dietary Restraint and Exercise on Appetite Control}

Exercise has been shown to be more effective than dieting in inducing a negative energy balance in the short term [51]. A study that compared the effects of a diet induced negative energy balance to an exercise induced negative energy balance found that hunger ratings and food cravings were significantly higher in the diet condition [51]. Another study that examined the impact of dietary restraint and a single bout of moderate-intensity exercise on post-exercise energy intake in sedentary 
males found that there was not a significant effect of exercise on energy intake either immediately after exercise or over a twelve hour time period [63]. The authors expected to find the overweight males with high restraint to become disinhibited by exercise and have significantly higher energy intakes but this was not observed. This could be attributed to the fact that increased energy expenditure from physical activity is not immediately compensated for by increases in energy expenditure [48]. A study on exercise, dietary restraint and energy intake in females who had recently lost weight found that exercise did not result in a significant increase in energy intake. This was not surprising since the majority of the subjects were classified as highly restrained. The subjects were also categorized into overeaters or undereaters depending on whether or not their self-selected energy intake levels exceeded their maintenance requirements. Compared to the undereaters, the overeaters had higher disinhibition scores [64].

\section{Queen's College Step Test}

Maximum oxygen uptake $\left(\mathrm{VO}_{2} \max \right)$ is a widely accepted measure of cardiorespiratory fitness. The experimental protocol used to determine $\mathrm{VO}_{2} \max$, however, is difficult, exhausting, and requires a well-equipped laboratory [65]. These factors have led to the development of simpler techniques to predict $\mathrm{VO}_{2} \max$. The Queen's College Step test is a frequently used 3 minute sub-maximal technique to estimate $\mathrm{VO}_{2} \max [66]$. Since the development of this indirect method of measuring $\mathrm{VO}_{2} \max$, studies have assessed its validity in different populations. The Queen's College step test was validated in male college students in India [67] but was found to 
be inaccurate for estimation in female college students in India [65]. Our analysis estimated $\mathrm{VO}_{2}$ max using a new equation for males that was recently developed at the University of Rhode Island. This equation was developed to more accurately estimate $\mathrm{VO}_{2} \mathrm{max}$ in males using heart rate and weight (Deborah Riebe, personal communication).

\section{Conclusion}

Since ghrelin's discovery in 1999 it has been studied extensively. Research has centered on its roles in appetite regulation, energy intake, and energy balance. Weight loss studies have demonstrated that ghrelin levels fluctuate with body weight. This along with the prevalence of obesity has highlighted the importance of research focused on body weight regulation on a hormonal level. Recent research has also explored the relationship between ghrelin and energy expenditure. The differences in type, duration, and intensity of the exercise protocols have made it difficult for a consensus to be made on the effects of exercise on ghrelin. Future studies in this area will help researchers understand the underlying mechanisms responsible for ghrelin's roles in both energy intake and energy expenditure. This present study will help to clarify previous findings and provide a better understanding of how fitness status and BMI relate to ghrelin and appetite. 


\section{REFERENCES}

1. St-Pierre, D.H., et al., Relationship between ghrelin and energy expenditure in healthy young women. J Clin Endocrinol Metab, 2004. 89(12): p. 5993-7.

2. Cummings, D.E., K.E. Foster-Schubert, and J. Overduin, Ghrelin and energy balance: focus on current controversies. Curr Drug Targets, 2005. 6(2): p. 153-69.

3. Cummings, D.E., Ghrelin and the short-and long-term regulation of appetite and body weight. Physiol Behav, 2006. 89(1): p. 71-84.

4. Shiiya, T., et al., Plasma ghrelin levels in lean and obese humans and the effect of glucose on ghrelin secretion. J Clin Endocrinol Metab, 2002. 87(1): p. 2404.

5. Hansen, T.K., et al., Weight loss increases circulating levels of ghrelin in human obesity. Clin Endocrinol (Oxf), 2002. 56(2): p. 203-6.

6. Leidy, H.J., et al., Circulating ghrelin is sensitive to changes in body weight during a diet and exercise program in normal-weight young women. $\mathrm{J}$ Clin Endocrinol Metab, 2004. 89(6): p. 2659-64.

7. Cummings, D.E., et al., Plasma ghrelin levels after diet-induced weight loss or gastric bypass surgery. N Engl J Med, 2002. 346(21): p. 1623-30.

8. Kraemer, R.R. and V.D. Castracane, Exercise and humoral mediators of peripheral energy balance: ghrelin and adiponectin. Exp Biol Med (Maywood), 2007. 232(2): p. 184-94.

9. Kojima, M., H. Hosoda, and K. Kangawa, Clinical endocrinology and metabolism. Ghrelin, a novel growth-hormone-releasing and appetite- 
stimulating peptide from stomach. Best Pract Res Clin Endocrinol Metab, 2004. 18(4): p. 517-30.

10. Tschop, M., D.L. Smiley, and M.L. Heiman, Ghrelin induces adiposity in rodents. Nature, 2000. 407(6806): p. 908-13.

11. Nakazato, M., et al., A role for ghrelin in the central regulation of feeding. Nature, 2001. 409(6817): p. 194-8.

12. Wren, A.M., et al., Ghrelin causes hyperphagia and obesity in rats. Diabetes, 2001. 50(11): p. 2540-7.

13. Druce, M.R., et al., Ghrelin increases food intake in obese as well as lean subjects. Int J Obes (Lond), 2005. 29(9): p. 1130-6.

14. Tschop, M., et al., Circulating ghrelin levels are decreased in human obesity. Diabetes, 2001. 50(4): p. 707-9.

15. Cummings, D.E., et al., A preprandial rise in plasma ghrelin levels suggests a role in meal initiation in humans. Diabetes, 2001.50(8): p. 1714-9.

16. Doucet, E., M. Pomerleau, and M.E. Harper, Fasting and postprandial total ghrelin remain unchanged after short-term energy restriction. J Clin Endocrinol Metab, 2004. 89(4): p. 1727-32.

17. Kojima, M., et al., Ghrelin is a growth-hormone-releasing acylated peptide from stomach. Nature, 1999. 402(6762): p. 656-60.

18. Tanaka-Shintani, M. and M. Watanabe, Distribution of ghrelinimmunoreactive cells in human gastric mucosa: comparison with that of parietal cells. J Gastroenterol, 2005. 40(4): p. 345-9. 
19. Ariyasu, H., et al., Stomach is a major source of circulating ghrelin, and feeding state determines plasma ghrelin-like immunoreactivity levels in humans. J Clin Endocrinol Metab, 2001. 86(10): p. 4753-8.

20. Sun, Y., et al., Ghrelin stimulation of growth hormone release and appetite is mediated through the growth hormone secretagogue receptor. Proc Natl Acad Sci U S A, 2004. 101(13): p. 4679-84.

21. Broglio, F., et al., Non-acylated ghrelin counteracts the metabolic but not the neuroendocrine response to acylated ghrelin in humans. J Clin Endocrinol Metab, 2004. 89(6): p. 3062-5.

22. Gauna, C., et al., Administration of acylated ghrelin reduces insulin sensitivity, whereas the combination of acylated plus unacylated ghrelin strongly improves insulin sensitivity. J Clin Endocrinol Metab, 2004. 89(10): p. 503542.

23. Gauna, C., et al., Ghrelin stimulates, whereas des-octanoyl ghrelin inhibits, glucose output by primary hepatocytes. J Clin Endocrinol Metab, 2005. 90(2): p. $1055-60$.

24. Thompson, N.M., et al., Ghrelin and des-octanoyl ghrelin promote adipogenesis directly in vivo by a mechanism independent of the type la growth hormone secretagogue receptor. Endocrinology, 2004. 145(1): p. 23442.

25. Foster-Schubert, K.E., et al., Human plasma ghrelin levels increase during a one-year exercise program. J Clin Endocrinol Metab, 2005. 90(2): p. 820-5. 
26. Schmidt, A., et al., Acute exercise has no effect on ghrelin plasma concentrations. Horm Metab Res, 2004. 36(3): p. 174-7.

27. Jurimae, J., T. Jurimae, and P. Purge, Plasma ghrelin is altered after maximal exercise in elite male rowers. Exp Biol Med (Maywood), 2007. 232(7): p. 9049.

28. Erdmann, J., et al., Plasma ghrelin levels during exercise - effects of intensity and duration. Regul Pept, 2007. 143(1-3): p. 127-35.

29. Burns, S.F., et al., A single session of treadmill running has no effect on plasma total ghrelin concentrations. J Sports Sci, 2007. 25(6): p. 635-42.

30. Broom, D.R., et al., Influence of resistance and aerobic exercise on hunger, circulating levels of acylated ghrelin, and peptide YY in healthy males. Am J Physiol Regul Integr Comp Physiol, 2009. 296(1): p. R29-35.

31. Leidy, H.J., et al., Twenty-four-hour ghrelin is elevated after calorie restriction and exercise training in non-obese women. Obesity (Silver Spring), 2007. 15(2): p. 446-55.

32. Monti, V., et al., Relationship of ghrelin and leptin hormones with body mass index and waist circumference in a random sample of adults. J Am Diet Assoc, 2006. 106(6): p. 822-8; quiz 829-30.

33. Morpurgo, P.S., et al., Ghrelin secretion in severely obese subjects before and after a 3-week integrated body mass reduction program. J Endocrinol Invest, 2003. 26(8): p. 723-7. 
34. St-Pierre, D.H., et al., Lifestyle behaviours and components of energy balance as independent predictors of ghrelin and adiponectin in young non-obese women. Diabetes Metab, 2006. 32(2): p. 131-9.

35. Makovey, J., et al., Gender differences in plasma ghrelin and its relations to body composition and bone - an opposite-sex twin study. Clin Endocrinol (Oxf), 2007. 66(4): p. 530-7.

36. De Souza, M.J., et al., Fasting ghrelin levels in physically active women: relationship with menstrual disturbances and metabolic hormones. J Clin Endocrinol Metab, 2004. 89(7): p. 3536-42.

37. Dafopoulos, K., et al., Blood ghrelin, resistin, and adiponectin concentrations during the normal menstrual cycle. Fertil Steril, 2008.

38. Melanson, K., Food intake regulation in body weight management. Nutrition Today, 2004. 39: p. 203-215.

39. King, N.A., A. Tremblay, and J.E. Blundell, Effects of exercise on appetite control: implications for energy balance. Med Sci Sports Exerc, 1997. 29(8): p. $1076-89$.

40. Thompson, D.A., L.A. Wolfe, and R. Eikelboom, Acute effects of exercise intensity on appetite in young men. Med Sci Sports Exerc, 1988. 20(3): p. 2227.

41. Kissileff, H.R., et al., Acute effects of exercise on food intake in obese and nonobese women. Am J Clin Nutr, 1990. 52(2): p. 240-5. 
42. King, N.A., V.J. Burley, and J.E. Blundell, Exercise-induced suppression of appetite: effects on food intake and implications for energy balance. Eur J Clin Nutr, 1994. 48(10): p. 715-24.

43. Blundell, J.E. and N.A. King, Effects of exercise on appetite control: loose coupling between energy expenditure and energy intake. Int J Obes Relat Metab Disord, 1998. 22 Suppl 2: p. S22-9.

44. George, V.A. and A. Morganstein, Effect of moderate intensity exercise on acute energy intake in normal and overweight females. Appetite, 2003. 40(1): p. $43-6$.

45. Blundell, J.E., et al., Cross talk between physical activity and appetite control: does physical activity stimulate appetite? Proc Nutr Soc, 2003. 62(3): p. 65161.

46. Broom, D.R., et al., Exercise-induced suppression of acylated ghrelin in humans. J Appl Physiol, 2007. 102(6): p. 2165-71.

47. Durrant, M.L., J.P. Royston, and R.T. Wloch, Effect of exercise on energy intake and eating patterns in lean and obese humans. Physiol Behav, 1982. 29(3): p. 449-54.

48. King, N.A., What processes are involved in the appetite response to moderate increases in exercise-induced energy expenditure? Proc Nutr Soc, 1999. 58(1): p. 107-13.

49. Lim, C.L. and L.K. Lee, The effects of 20 weeks basic military training program on body composition, VO2max and aerobic fitness of obese recruits. $\mathrm{J}$ Sports Med Phys Fitness, 1994. 34(3): p. 271-8. 
50. Martins, C., M.D. Robertson, and L.M. Morgan, Effects of exercise and restrained eating behaviour on appetite control. Proc Nutr Soc, 2008. 67(1): p. $28-41$.

51. Hubert, P., N.A. King, and J.E. Blundell, Uncoupling the effects of energy expenditure and energy intake: appetite response to short-term energy deficit induced by meal omission and physical activity. Appetite, 1998. 31(1): p. 9-19.

52. Martins, C., et al., Effects of exercise on gut peptides, energy intake and appetite. J Endocrinol, 2007. 193(2): p. 251-8.

53. Rogers, P.J., Eating habits and appetite control: a psychobiological perspective. Proc Nutr Soc, 1999. 58(1): p. 59-67.

54. Byrant, E., King, N., Blundell, J., Effect of exercise on appetite control in women with high trait disinhibition. Appetite, 2005. 45 p. 363.

55. Martins, C., L.M. Morgan, and M.D. Robertson, Effects of restrained eating behaviour on insulin sensitivity in normal-weight individuals. Physiol Behav, 2009. 96(4-5): p. 703-8.

56. Herman, C.P. and D. Mack, Restrained and unrestrained eating. J Pers, 1975. 43(4): p. $647-60$.

57. Pirke, K.M., et al., Endocrine findings in restrained eaters. Physiol Behav, 1990. 47(5): p. 903-6.

58. Westerterp-Plantenga, M.S., et al., Diet-induced thermogenesis and cumulative food intake curves as a function of familiarity with food and dietary restraint in humans. Physiol Behav, 1992. 51(3): p. 457-65. 
59. Keim, N.L. and W.F. Horn, Restrained eating behavior and the metabolic response to dietary energy restriction in women. Obes Res, 2004. 12(1): p. $141-9$

60. de Lauzon-Guillain, B., Basdevant, A., Romon, M., Karlsson, J., Borys, J.M., Charles, M.A., The FLVS Study Group Is restrained eating a risk factor for weight gain in a general population? Am J Clin Nutr, 2006. 83: p. 132-138.

61. Lluch, A., et al., Dietary intakes, eating style and overweight in the Stanislas Family Study. Int J Obes Relat Metab Disord, 2000. 24(11): p. 1493-9.

62. Bryant, E.J., N.A. King, and J.E. Blundell, Disinhibition: its effects on appetite and weight regulation. Obes Rev, 2008. 9(5): p. 409-19.

63. Harris, C.L. and V.A. George, The impact of dietary restraint and moderateintensity exercise on post-exercise energy intake in sedentary males. Eat Behav, 2008. 9(4): p. 415-22.

64. Keim, N.L., et al., Effect of exercise and dietary restraint on energy intake of reduced-obese women. Appetite, 1996. 26(1): p. 55-70.

65. Chatterjee, S., P. Chatterjee, and A. Bandyopadhyay, Validity of Queen's College Step Test for estimation of maximum oxygen uptake in female students. Indian J Med Res, 2005. 121(1): p. 32-5:

66. McArdle, W.D., et al., Reliability and interrelationships between maximal oxygen intake, physical work capacity and step-test scores in college women. Med Sci Sports, 1972. 4(4): p. 182-6.

67. Chatterjee, S., et al., Validity of Queen's College step test for use with young Indian men. Br J Sports Med, 2004. 38(3): p. 289-91. 


\section{APPENDIX B}

\section{INTERNATIONAL PHYSICAL ACTIVITY QUESTIONNAIRE}

We are interested in finding out about the kinds of physical activities that people do as part of their everyday lives. The questions will ask you about the time you spent being physically active in the last 7 days. Please answer each question even if you do not consider yourself to be an active person. Please think about the activities you do at work, as part of your house and yard work, to get from place to place, and in your spare time for recreation, exercise or sport.

Think about all the vigorous activities that you did in the last 7 days.

Vigorous physical activities refer to activities that take hard physical effort and make you breathe much harder than normal. Think only about those physical activities that you did for at least 10 minutes at a time.

1. During the last $\mathbf{7}$ days, on how many days did you do vigorous physical activities like heavy lifting, digging, aerobics, or fast bicycling? days per week<smiles>C1CCC1</smiles>

No vigorous physical activities $\rightarrow$ Skip to question 3

2. How much time did you usually spend doing vigorous physical activities on one of those days?

hours per day

minutes per day

$\square$ Don't know/Not sure 
Think about all the moderate activities that you did in the last 7 days. Moderate activities refer to activities that take moderate physical effort and make you breathe somewhat harder than normal. Think only about those physical activities that you did for at least 10 minutes at a time.

3. During the last $\mathbf{7}$ days, on how many days did you do moderate physical activities like carrying light loads, bicycling at a regular pace, or doubles tennis? Do not include walking. days per week

No moderate physical activities $\rightarrow$ Skip to question 5

4. How much time did you usually spend doing moderate physical activities on one of those days?

hours per day minutes per day

$\square$ Don't know/Not sure

Think about the time you spent walking in the last 7 days. This includes at work and at home, walking to travel from place to place, and any other walking that you might do solely for recreation, sport, exercise, or leisure.

5. During the last $\mathbf{7}$ days, on how many days did you walk for at least 10 minutes at a time? days per week

$\square$ No walking $\longrightarrow$ Skip to question 7

6. How much time did you usually spend walking on one of those days? hours per day minutes per day

$\square$ Don't know/Not sure 
The last question is about the time you spent sitting on weekdays during the last 7 days. Include time spent at work, at home, while doing course work and during leisure time. This may include time spent sitting at a desk, visiting friends, reading, or sitting or lying down to watch television.

7. During the last $\mathbf{7}$ days, how much time did you spend sitting on a week day?

hours per day

minutes per day

Don't know/Not sure

This is the end of the questionnaire, thank you for participating. 


\section{APPENDIX C}

\section{Three-Factor Eating Questionnaire}

For the true/false items on the next two pages, indicate whether or not you feel or behave that way by selecting whether the statement is TRUE or FALSE for you by carefully placing a check $(\checkmark)$ in the box that represents either true or false.

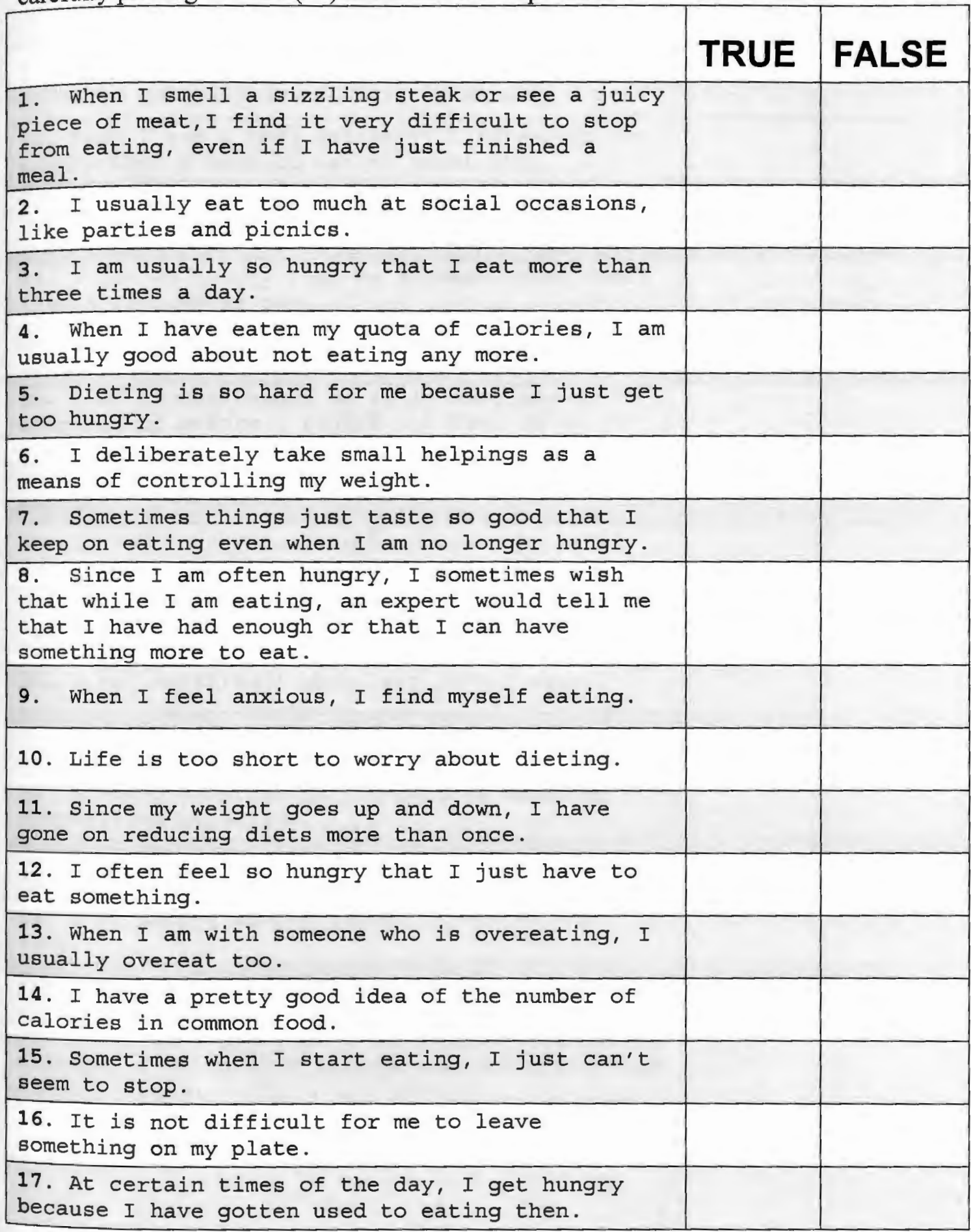




\begin{tabular}{|c|c|c|}
\hline & TRUE & FALSE \\
\hline $\begin{array}{l}\text { 18. While on a diet, if I eat food that is not } \\
\text { allowed, I consciously eat less for a period of } \\
\text { time to make up for it. }\end{array}$ & & \\
\hline $\begin{array}{l}\text { 19. Being with someone who is eating often makes } \\
\text { me hungry enough to eat also. }\end{array}$ & & \\
\hline 20. When I feel blue, I often overeat. & & \\
\hline $\begin{array}{l}\text { 21. I enjoy eating too much to spoil it by } \\
\text { counting calories or watching my weight. }\end{array}$ & & \\
\hline $\begin{array}{l}\text { 22. When I see a real delicacy, I often get so } \\
\text { hungry that I have to eat it right away. }\end{array}$ & & \\
\hline $\begin{array}{l}\text { 23. I often stop eating when I am not really } \\
\text { fuli as a conscious means of limiting the amount } \\
\text { that I eat. }\end{array}$ & & \\
\hline $\begin{array}{l}\text { 24. I get so hungry that my stomach often feels } \\
\text { like a bottomless pit. }\end{array}$ & & \\
\hline $\begin{array}{l}\text { 25. My weight has hardly changed at all in the } \\
\text { last ten years. }\end{array}$ & & \\
\hline $\begin{array}{l}\text { 26. I am always hungry so it is hard for me to } \\
\text { stop eating before I finish the food on my } \\
\text { plate. }\end{array}$ & & \\
\hline $\begin{array}{l}\text { 27. When I feel lonely, I console myself by } \\
\text { eating. }\end{array}$ & & \\
\hline $\begin{array}{l}\text { 28. I consciously hold back at meals in order } \\
\text { not to gain weight. }\end{array}$ & & \\
\hline $\begin{array}{l}\text { 29. I sometimes get very hungry late in the } \\
\text { evening or at night. }\end{array}$ & & \\
\hline 30. I eat anything I want, any time I want. & & \\
\hline $\begin{array}{l}\text { 31. Without even thinking about it, I take a } \\
\text { long time to eat. }\end{array}$ & & \\
\hline $\begin{array}{l}\text { 32. I count calories as a conscious means of } \\
\text { controlling my weight. }\end{array}$ & & \\
\hline $\begin{array}{l}\text { 33. I do not eat some foods because they make me } \\
\text { fat. }\end{array}$ & & \\
\hline $\begin{array}{l}\text { 34. I am always hungry enough to eat at any } \\
\text { time. }\end{array}$ & & \\
\hline $\begin{array}{l}\text { 35. I pay a great deal of attention to changes } \\
\text { in my figure. }\end{array}$ & & \\
\hline $\begin{array}{l}\text { 36. While on a diet, if I eat a food that is not } \\
\text { allowed, I often then splurge and eat other high } \\
\text { calorie foods. }\end{array}$ & & \\
\hline
\end{tabular}


Please answer the questions in this section by circling the number above the response that is appropriate for you.

37. How often are you dieting in a conscious effort to control your weight?

1

rarely
2

sometimes
3

usually
4 always

38. Would a weight fluctuation of 5 lbs affect the way you live your life?

$\begin{array}{llll}1 & 2 & 3 & 4 \\ \text { not at all } & \text { slightly } & \text { moderately } & \text { very much }\end{array}$

39. How often do you feel hungry?

$\begin{array}{llll}1 & 2 & 3 & 4 \\ \text { only at } & \text { sometimes } & \text { often } & \text { almost } \\ \text { mealtimes } & \text { between meals } & \text { between meals } & \text { always }\end{array}$

40. Do your feelings of guilt about overeating help you to control your food intake?
1
never
2
rarely
3
often
4
always

41. How difficult would it be for you to stop eating halfway through dinner and not eat for the next four hours?
1
2
3
4
easy
slightly
moderately
difficult
very
difficult
difficult

42. How conscious are you of what you are eating?
1
2
3
4
not at all
slightly
moderately
extremely

43. How frequently do you avoid "stocking up" on tempting foods?

$\begin{array}{llll}1 & 2 & 3 & 4 \\ \text { aimost never } & \text { seldom } & \text { usually } & \text { almost } \\ & & & \text { always }\end{array}$

44. How likely are you to shop for low calorie foods?

$\begin{array}{llll}1 & 2 & 3 & 4 \\ \text { unlikely } & \text { slightly } & \text { moderately } & \text { very } \\ & \text { likely } & \text { likely } & \text { likely }\end{array}$


45. Do you eat sensibly in front of others and splurge alone?
1
2
never
rarely
3
often
4
always

46. How likely are you to consciously eat slowly in order to cut down on how much you eat?
1
2
3
4
unlikely
slightly
likely
moderately
likely
very
likely

47. How frequently do you skip dessert because you are no longer hungry?

$\begin{array}{llll}1 & 2 & 3 & 4 \\ \text { almost } & \text { seldom } & \text { at least } & \text { almost } \\ \text { never } & & \text { once a week } & \text { every day }\end{array}$

48. How likely are you to consciously eat less than you want?

$\begin{array}{llll}1 & 2 & 3 & 4 \\ \text { unlikely } & \text { slightly } & \text { moderately } & \text { very } \\ & \text { likely } & \text { likely } & \text { likely }\end{array}$

49. Do you go on eating binges though you are not hungry?

1

never
2

rarely
3

sometimes
4

at least

once a week

50. On a scale of 0 to 5 , where 0 means no restraint in eating (eating whatever you

want, whenever you want it) and 5 means total restraint (constantly limiting food intake and never 'giving in'), what number would you give yourself? Please circle your answer.

0--eat whatever you want, whenever you want it

1--usually eat whatever you want, whenever you want it

2--often eat whatever you want, whenever you want it

3--often limit food intake, but often 'give in'

4--usually limit food intake, rarely 'give in'

5--constantly limiting food intake, never 'giving in' 
51. To what extent does this statement describe your eating behavior? 'I start dieting in the morning, but because of any number of things that happen during the day, by evening I have given up and eat what I want, promising myself to start dieting again tomorrow.'

1

not like me
2

little like me
3

pretty good description of me
4 describes me perfectly 


\section{Energy Metabolism Laboratory Satiety Rating Scale}

\begin{tabular}{|l|l|l|l|}
\hline Subject \# & Test Condition & Visit \# & Visit Date \\
\hline & & & \\
\hline
\end{tabular}

Please answer each question by placing a small vertical hash (" $"$ ") across the horizontal line at the point that best reflects your present feelings.

Clock Time:

1. How hungry are you right now?

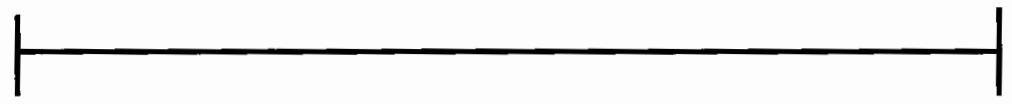

Not at all

Extremely

2. How satisfied (satiated) are you right now?

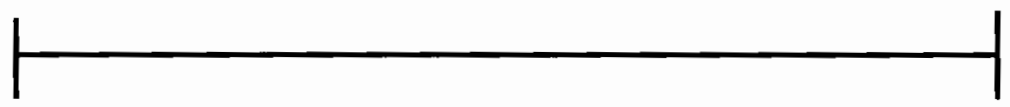

Not at all

Extremely

3. How much could you eat right now?

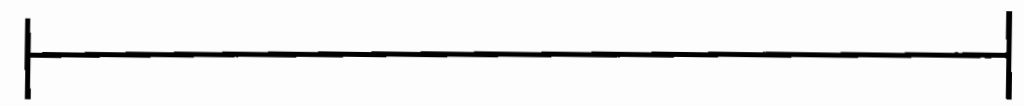

Nothing

Vast Quantities 


\section{BIBLIOGRAPHY}

Ariyasu, H., K. Takaya, et al. (2001). "Stomach is a major source of circulating ghrelin, and feeding state determines plasma ghrelin-like immunoreactivity levels in humans." J Clin Endocrinol Metab 86(10): 4753-8.

Blom, W. A., A. Lluch, et al. (2006). "Effect of a high-protein breakfast on the postprandial ghrelin response." Am J Clin Nutr 83(2): 211-20.

Blundell, J. E. and N. A. King (1998). "Effects of exercise on appetite control: loose coupling between energy expenditure and energy intake." Int J Obes Relat Metab Disord 22 Suppl 2: S22-9.

Blundell, J. E., R. J. Stubbs, et al. (2003). "Cross talk between physical activity and appetite control: does physical activity stimulate appetite?" Proc Nutr Soc 62(3): 651-61.

Broglio, F., C. Gottero, et al. (2004). "Non-acylated ghrelin counteracts the metabolic but not the neuroendocrine response to acylated ghrelin in humans." J Clin Endocrinol Metab 89(6): 3062-5.

Broom, D. R., R. L. Batterham, et al. (2009). "Influence of resistance and aerobic exercise on hunger, circulating levels of acylated ghrelin, and peptide YY in healthy males." Am J Physiol Regul Integr Comp Physiol 296(1): R29-35.

Broom, D. R., D. J. Stensel, et al. (2007). "Exercise-induced suppression of acylated ghrelin in humans." J Appl Physiol 102(6): 2165-71.

Bryant, E. J., N. A. King, et al. (2008). "Disinhibition: its effects on appetite and weight regulation." Obes Rev 9(5): 409-19. 
Burns, S. F., D. R. Broom, et al. (2007). "A single session of treadmill running has no effect on plasma total ghrelin concentrations." J Sports Sci 25(6): 635-42.

Byrant, E., King, N., Blundell, J. (2005). "Effect of exercise on appetite control in women with high trait disinhibition." Appetite 45: 363.

Chatterjee, S., P. Chatterjee, et al. (2005). "Validity of Queen's College Step Test for estimation of maximum oxygen uptake in female students." Indian J Med Res 121(1): $32-5$.

Chatterjee, S., P. Chatterjee, et al. (2004). "Validity of Queen's College step test for use with young Indian men." Br J Sports Med 38(3): 289-91.

Craig, C. L., A. L. Marshall, et al. (2003). "International physical activity questionnaire: 12-country reliability and validity." Med Sci Sports Exerc 35(8): 1381-95.

Cummings, D. E. (2006). "Ghrelin and the short- and long-term regulation of appetite and body weight." Physiol Behav 89(1): 71-84.

Cummings, D. E., K. E. Foster-Schubert, et al. (2005). "Ghrelin and energy balance: focus on current controversies." Curr Drug Targets 6(2): 153-69.

Cummings, D. E., J. Q. Purnell, et al. (2001). "A preprandial rise in plasma ghrelin levels suggests a role in meal initiation in humans." Diabetes 50(8): 1714-9. Cummings, D. E., D. S. Weigle, et al. (2002). "Plasma ghrelin levels after diet-induced weight loss or gastric bypass surgery." N Engl J Med 346(21): 1623-30.

Dafopoulos, K., D. Sourlas, et al. (2008). "Blood ghrelin, resistin, and adiponectin concentrations during the normal menstrual cycle." Fertil Steril. 
Dall, R., J. Kanaley, et al. (2002). "Plasma ghrelin levels during exercise in healthy subjects and in growth hormone-deficient patients." Eur J Endocrinol 147(1): $65-70$.

de Graaf, C., W. A. Blom, et al. (2004). "Biomarkers of satiation and satiety." Am J Clin Nutr 79(6): 946-61.

de Lauzon-Guillain, B., Basdevant, A., Romon, M., Karlsson, J., Borys, J.M., Charles, M.A., The FLVS Study Group (2006). "Is restrained eating a risk factor for weight gain in a general population?" Am J Clin Nutr 83: 132-138.

De Souza, M. J., H. J. Leidy, et al. (2004). "Fasting ghrelin levels in physically active women: relationship with menstrual disturbances and metabolic hormones." $\underline{\mathrm{J}}$ Clin Endocrinol Metab 89(7): 3536-42.

Doucet, E., M. Pomerleau, et al. (2004). "Fasting and postprandial total ghrelin remain unchanged after short-term energy restriction." J Clin Endocrinol Metab 89(4): $1727-32$.

Druce, M. R., A. M. Wren, et al. (2005). "Ghrelin increases food intake in obese as well as lean subjects." Int J Obes (Lond) 29(9): 1130-6.

Durrant, M. L., J. P. Royston, et al. (1982). "Effect of exercise on energy intake and eating patterns in lean and obese humans." Physiol Behav 29(3): 449-54.

Erdmann, J., R. Tahbaz, et al. (2007). "Plasma ghrelin levels during exercise - effects of intensity and duration." Regul Pept 143(1-3): 127-35.

Erdmann, J., R. Topsch, et al. (2004). "Postprandial response of plasma ghrelin levels to various test meals in relation to food intake, plasma insulin, and glucose." $\underline{\mathrm{J}}$ Clin Endocrinol Metab 89(6): 3048-54. 
Fields, D. A., M. I. Goran, et al. (2002). "Body-composition assessment via airdisplacement plethysmography in adults and children: a review." Am J Clin Nutr 75(3): 453-67.

Flint, A., A. Raben, et al. (2000). "Reproducibility, power and validity of visual analogue scales in assessment of appetite sensations in single test meal studies." Int J Obes Relat Metab Disord 24(1): 38-48.

Foster-Schubert, K. E., A. McTiernan, et al. (2005). "Human plasma ghrelin levels increase during a one-year exercise program." J Clin Endocrinol Metab 90(2): $820-5$.

Gauna, C., P. J. Delhanty, et al. (2005). "Ghrelin stimulates, whereas des-octanoyl ghrelin inhibits, glucose output by primary hepatocytes." J Clin Endocrinol Metab 90(2): 1055-60.

Gauna, C., F. M. Meyler, et al. (2004). "Administration of acylated ghrelin reduces insulin sensitivity, whereas the combination of acylated plus unacylated ghrelin strongly improves insulin sensitivity." J Clin Endocrinol Metab 89(10): $5035-42$

George, V. A. and A. Morganstein (2003). "Effect of moderate intensity exercise on acute energy intake in normal and overweight females." Appetite 40(1): 43-6.

Hansen, T. K., R. Dall, et al. (2002). "Weight loss increases circulating levels of ghrelin in human obesity." Clin Endocrinol (Oxf) 56(2): 203-6.

Harris, C. L. and V. A. George (2008). "The impact of dietary restraint and moderateintensity exercise on post-exercise energy intake in sedentary males." Eat Behav 9(4): 415-22. 
Herman, C. P. and D. Mack (1975). "Restrained and unrestrained eating." J Pers 43(4): $647-60$.

Hubert, P., N. A. King, et al. (1998). "Uncoupling the effects of energy expenditure and energy intake: appetite response to short-term energy deficit induced by meal omission and physical activity." Appetite 31(1): 9-19.

Jurimae, J., P. Hofmann, et al. (2007). "Plasma ghrelin responses to acute sculling exercises in elite male rowers." Eur J Appl Physiol 99(5): 467-74.

Jurimae, J., T. Jurimae, et al. (2007). "Plasma ghrelin is altered after maximal exercise in elite male rowers." Exp Biol Med (Maywood) 232(7): 904-9.

Keim, N. L., D. J. Canty, et al. (1996). "Effect of exercise and dietary restraint on energy intake of reduced-obese women." Appetite 26(1): 55-70.

Keim, N. L. and W. F. Horn (2004). "Restrained eating behavior and the metabolic response to dietary energy restriction in women." Obes Res 12(1): 141-9.

King, N. A. (1999). "What processes are involved in the appetite response to moderate increases in exercise-induced energy expenditure?" Proc Nutr Soc 58(1): $107-$ 13.

King, N. A., V. J. Burley, et al. (1994). "Exercise-induced suppression of appetite: effects on food intake and implications for energy balance." Eur J Clin Nutr 48(10): 715-24.

King, N. A., A. Tremblay, et al. (1997). "Effects of exercise on appetite control: implications for energy balance." Med Sci Sports Exerc 29(8): 1076-89.

Kissileff, H. R., F. X. Pi-Sunyer, et al. (1990). "Acute effects of exercise on food intake in obese and nonobese women." Am J Clin Nutr 52(2): 240-5. 
Kojima, M., H. Hosoda, et al. (1999). "Ghrelin is a growth-hormone-releasing acylated peptide from stomach." Nature 402(6762): 656-60.

Kojima, M., H. Hosoda, et al. (2004). "Clinical endocrinology and metabolism. Ghrelin, a novel growth-hormone-releasing and appetite-stimulating peptide from stomach." Best Pract Res Clin Endocrinol Metab 18(4): 517-30.

Kopelman, P. G. (2000). "Obesity as a medical problem." Nature 404(6778): 635-43.

Kraemer, R. R. and V. D. Castracane (2007). "Exercise and humoral mediators of peripheral energy balance: ghrelin and adiponectin." Exp Biol Med (Maywood) 232(2): 184-94.

Kraemer, R. R., R. J. Durand, et al. (2004). "Rigorous running increases growth hormone and insulin-like growth factor-I without altering ghrelin." Exp Biol Med (Maywood) 229(3): 240-6.

Leidy, H. J., K. A. Dougherty, et al. (2007). "Twenty-four-hour ghrelin is elevated after calorie restriction and exercise training in non-obese women." Obesity (Silver Spring) 15(2): 446-55.

Leidy, H. J., J. K. Gardner, et al. (2004). "Circulating ghrelin is sensitive to changes in body weight during a diet and exercise program in normal-weight young women." J Clin Endocrinol Metab 89(6): 2659-64.

Lim, C. L. and L. K. Lee (1994). "The effects of 20 weeks basic military training program on body composition, VO2max and aerobic fitness of obese recruits." J Sports Med Phys Fitness 34(3): 271-8.

Lluch, A., B. Herbeth, et al. (2000). "Dietary intakes, eating style and overweight in the Stanislas Family Study." Int J Obes Relat Metab Disord 24(11): 1493-9. 
Makovey, J., V. Naganathan, et al. (2007). "Gender differences in plasma ghrelin and its relations to body composition and bone - an opposite-sex twin study." $\underline{\text { Clin }}$ Endocrinol (Oxf) 66(4): 530-7.

Martins, C., L. M. Morgan, et al. (2007). "Effects of exercise on gut peptides, energy intake and appetite." J Endocrinol 193(2): 251-8.

Martins, C., L. M. Morgan, et al. (2009). "Effects of restrained eating behaviour on insulin sensitivity in normal-weight individuals." Physiol Behav 96(4-5): 7038.

Martins, C., M. D. Robertson, et al. (2008). "Effects of exercise and restrained eating behaviour on appetite control." Proc Nutr Soc 67(1): 28-41.

McArdle, W. D., F. I. Katch, et al. (1972). "Reliability and interrelationships between maximal oxygen intake, physical work capacity and step-test scores in college women." Med Sci Sports 4(4): 182-6.

Melanson, K. (2004). "Food intake regulation in body weight management." Nutrition Today 39: 203-215.

Monti, V., J. J. Carlson, et al. (2006). "Relationship of ghrelin and leptin hormones with body mass index and waist circumference in a random sample of adults." J Am Diet Assoc 106(6): 822-8; quiz 829-30.

Moore, S. C. (2009). "Waist versus weight: which matters more for mortality?" Am J Clin Nutr 89(4): 1003-4.

Morpurgo, P. S., M. Resnik, et al. (2003). "Ghrelin secretion in severely obese subjects before and after a 3-week integrated body mass reduction program." $\underline{J}$ Endocrinol Invest 26(8): 723-7. 
Nakazato, M., N. Murakami, et al. (2001). "A role for ghrelin in the central regulation of feeding." Nature 409(6817): 194-8.

Pirke, K. M., R. J. Tuschl, et al. (1990). "Endocrine findings in restrained eaters." Physiol Behav 47(5): 903-6.

Rogers, P. J. (1999). "Eating habits and appetite control: a psychobiological perspective." Proc Nutr Soc 58(1): 59-67.

Schmidt, A., C. Maier, et al. (2004). "Acute exercise has no effect on ghrelin plasma concentrations." Horm Metab Res 36(3): 174-7.

Shiiya, T., M. Nakazato, et al. (2002). "Plasma ghrelin levels in lean and obese humans and the effect of glucose on ghrelin secretion." J Clin Endocrinol Metab 87(1): 240-4.

Siri, W. (1961). Body composition from fluid spaces and density. In: Techniques for measuring body composition. . Washington, DC, National Academy of Sciences.

Speakman, J. R. and C. Selman (2003). "Physical activity and resting metabolic rate." Proc Nutr Soc 62(3): 621-34.

St-Pierre, D. H., M. Faraj, et al. (2006). "Lifestyle behaviours and components of energy balance as independent predictors of ghrelin and adiponectin in young non-obese women." Diabetes Metab 32(2): 131-9.

St-Pierre, D. H., A. D. Karelis, et al. (2004). "Relationship between ghrelin and energy expenditure in healthy young women." J Clin Endocrinol Metab 89(12): 59937. 
Stunkard, A. J. and S. Messick (1985). "The three-factor eating questionnaire to measure dietary restraint, disinhibition and hunger." J Psychosom Res 29(1): $71-83$

Sun, Y., P. Wang, et al. (2004). "Ghrelin stimulation of growth hormone release and appetite is mediated through the growth hormone secretagogue receptor." Proc Natl Acad Sci U S A 101(13): 4679-84.

Tanaka-Shintani, M. and M. Watanabe (2005). "Distribution of ghrelinimmunoreactive cells in human gastric mucosa: comparison with that of parietal cells." J Gastroenterol 40(4): 345-9.

Thompson, D. A., L. A. Wolfe, et al. (1988). "Acute effects of exercise intensity on appetite in young men." Med Sci Sports Exerc 20(3): 222-7.

Thompson, N. M., D. A. Gill, et al. (2004). "Ghrelin and des-octanoyl ghrelin promote adipogenesis directly in vivo by a mechanism independent of the type la growth hormone secretagogue receptor." Endocrinology 145(1): 234-42.

Tschop, M., D. L. Smiley, et al. (2000). "Ghrelin induces adiposity in rodents." Nature 407(6806): 908-13.

Tschop, M., C. Weyer, et al. (2001). "Circulating ghrelin levels are decreased in human obesity." Diabetes 50(4): 707-9.

Westerterp-Plantenga, M. S., E. Van den Heuvel, et al. (1992). "Diet-induced thermogenesis and cumulative food intake curves as a function of familiarity with food and dietary restraint in humans." Physiol Behav 51(3): 457-65.

Wren, A. M., C. J. Small, et al. (2001). "Ghrelin causes hyperphagia and obesity in rats." Diabetes 50(11): 2540-7. 